\title{
Synthesis and characterization of magnetic recyclable Fe-substituted zinc aluminate photocatalysts with enhanced sunlight-driven degradation of industrial dyes
}

Thanit Tangcharoen ( $\nabla$ sfscitnt@ku.ac.th )

Kasetsart University Sriracha Campus https://orcid.org/0000-0003-1273-4434

Jiraroj T-Thienprasert

Kasetsart University Faculty of Science

Chanapa Kongmark

Kasetsart University Faculty of Science

\section{Research Article}

Keywords: XRD, FT-IR, SEM, EDS, BET, UV-DRS, VSM

Posted Date: December 10th, 2020

DOl: https://doi.org/10.21203/rs.3.rs-123796/v1

License: (c) (1) This work is licensed under a Creative Commons Attribution 4.0 International License.

Read Full License 


\title{
Synthesis and characterization of magnetic recyclable Fe- substituted zinc aluminate photocatalysts with enhanced sunlight-driven degradation of industrial dyes
}

\author{
Thanit Tangcharoen ${ }^{1, *}$, Jiraroj T-Thienprasert ${ }^{2}$, and Chanapa Kongmark ${ }^{3}$ \\ ${ }^{1}$ Department of Basic Science and Physical Education, Faculty of Science at Sriracha, Kasetsart \\ University, Sriracha Campus, Chonburi 20230, Thailand \\ ${ }^{2}$ Department of Physics, Faculty of Science, Kasetsart University, Bangkok 10900, Thailand \\ ${ }^{3}$ Specialized center of Rubber and Polymer Materials in agriculture and industry (RPM), \\ Department of Materials Science, Faculty of Science, Kasetsart University, Bangkok 10900, \\ Thailand \\ ${ }^{*}$ Corresponding author's e-mail: sfscitnt@ku.ac.th
}

\begin{abstract}
Using the sol-gel auto combustion approach with diethanolamine (DEA) as fuel, a sequence of iron-substituted zinc aluminates, $\mathrm{ZnFe}_{\mathrm{x}} \mathrm{Al}_{2-\mathrm{x}} \mathrm{O}_{4}$ powders, including variable $\mathrm{Fe}^{3+}$ ion concentrations $(0 \leq x \leq 2)$ were effectively created. XRD, FT-IR, SEM, EDS, BET, UV-DRS, and VSM were employed to examine the structures, chemical bonds, morphologies, composition, surface area, and optical properties as well as the magnetic behavior of the collected samples. A single-phase spinel structure was gained for the calcined aluminate powders with different interplanar spacing and crystallite sizes, as revealed by the classification results. The bandgap energy $\left(E_{g}\right)$ of adapted aluminates was in the range of $2.08-3.14 \mathrm{eV}$, identified as being much lower compared to the pure sample $(5.60 \mathrm{eV})$. Thus, $\mathrm{Fe}^{3+}$-substituted $\mathrm{ZnAl}_{2} \mathrm{O}_{4}$ samples could be successfully photoexcited using both ultraviolet and visible light, as suggested by the results. Examination of how the four main pollutant types decay when irradiated by sunlight was carried out to assess the samples and establish photocatalytic activity. These contaminants included phenol rhodamine $\mathrm{B}(\mathrm{RhB})$, heteropolyaromatic methylene blue (MB), azoic methyl orange (MO) and methyl red (MR). The performance of photocatalytic degradation reached $98 \%$ after 150 minutes for all optimal samples of organic dyes. Besides, each of the altered photocatalysts could be recycled and displayed high stability. The $\mathrm{S}$-shaped curve of ferrimagnetism can result from in those samples as found by the magnetic measurements, though pure $\mathrm{ZnAl}_{2} \mathrm{O}_{4}$ displays diamagnetic characteristics. The adapted samples show intense improvement in the remanent magnetization $\left(M_{r}\right)$ when compared to pure $\mathrm{ZnAl}_{2} \mathrm{O}_{4}$, signifying that magnetic photocatalyst recovery by applying an external magnetic field is easy. Thus, these results offer a convincing sign that $\mathrm{ZnAl}_{2} \mathrm{O}_{4}$ powders
\end{abstract}


replaced by $\mathrm{Fe}^{3+}$ could provide the ability to aid in the ecologically-friendly collection of solar energy.

\section{Introduction}

In recent years, environmental contamination levels have risen, in part as a result of the activity of the textile industry, with the introduction of many harmful organic dyes into the ecosystem by industrial effluents [1, 2]. Including ozone treatment, biological containment, adsorption, and photocatalytic degradation, various approaches have been used to try to eradicate hazardous contaminants [3-5]. Between these strategies, the most useful is photocatalytic degradation, which also provides the benefit of being the least harmful to the environment because it depends heavily on light to disintegrate the contaminants [6]. The approach uses a light-responsive semiconductor in which photo-induced electron-hole pairs are separated into valance and conduction bands, and the transmission enables them to oxidize water or oxygen molecules to produce active radical species that can then degrade organic contaminants [7, 8]. Various materials have been the emphasis of investigation, such as several metal oxides and semiconductors, to support the process of eradicating environmental contamination as photocatalysts. Still, there is also the necessity to seek new photocatalysts focused on improved use of solar energy and renewable capabilities in order to establish a more realistic and ecologically responsible process [9, 10]. To produce such novel photocatalysts, a range of technical methods have been proposed, including flexible doping, crystal facet regulation, crystal morphology modulation, or heterojunction construction. Boosting the overall performance of a modern type of photocatalyst is the overall goal [11].

Zinc aluminate $\left(\mathrm{ZnAl}_{2} \mathrm{O}_{4}\right)$, a semiconductor with wide-bandgap properties $(\geq 4.0 \mathrm{eV})$, is a potential photocatalyst that provides the capacity to produce hydrogen, restrain carbon dioxide, and transfigure organic pollutants [12]. The capacity to use solar energy is reduced, with the photoabsorption spectrum making up only $4 \%$ of available sunlight when $\mathrm{ZnAl}_{2} \mathrm{O}_{4}$ acts as a photocatalyst, which is a shortcoming [13]. Including crystal facet control, hierarchical nanostructures, halogen-mixing solid solutions, or the creation of heterojunctions by coupling with other materials, several solutions for this topic have been proposed [14, 15]. The benefit of heterojunction photocatalysts is that the discrete functions are combined into a single framework and therefore provide hybrid multiple synergistic features, including a broad range of light reaction and low electron-hole recombination rates. These characteristics help to greatly enhance the level of photocatalytic activity $[16,17]$. Besides, a more successful boost to operation can be obtained from metal doping, based on the capacity of doped metal to capture photo-induced load carriers, thereby reducing the semiconductor photocatalyst bandgap. To generate $\mathrm{Co}^{2+}$ and $\mathrm{Ni}^{2+}$-substituted $\mathrm{ZnAl}_{2} \mathrm{O}_{4}$ nanopowders to formulate $\mathrm{Co}_{\mathrm{x}} \mathrm{Zn}_{1-\mathrm{x}} \mathrm{Al}_{2} \mathrm{O}_{4}$ and $\mathrm{Ni}_{\mathrm{x}} \mathrm{Zn}_{1-\mathrm{x}} \mathrm{Al}_{2} \mathrm{O}_{4}$, the microwave combustion approach was used by Anand et al. [18,19 ]They registered a constant decrease in the energy bandgap $\left(E_{g}\right)$ as $\mathrm{Co}^{2+}$ and $\mathrm{Ni}^{2+}$ substitution was increased, preliminarily at $5.01 \mathrm{eV}$ to $2.89 \mathrm{eV}$ and $3.49 \mathrm{eV}$, thus boosting the electromagnetic wave in the visible light region. By adding $\mathrm{Mn}^{2+}$ ions into the crystal structure with compositions of $\mathrm{Zn}_{1-\mathrm{x}} \mathrm{Mn}_{\mathrm{x}} \mathrm{Al}_{2} \mathrm{O}_{4}$, they also researched the tunable band-gap energy of $\mathrm{ZnAl}_{2} \mathrm{O}_{4}$ in addition to varying dilutions of additive ions. Achieving the lowest 
values of $3.49 \mathrm{eV}$, the $E_{g}$ of manganese-substituted zinc aluminate samples decreased steadily with the rise of $\mathrm{Mn}^{2+}$ concentrations [20]. Still, the added ion value in their studies was restricted to $x=$ 0.5. At the same time, the production of mesoporous $\mathrm{Co}^{2+}$ and $\mathrm{Ni}^{2+}$-substituted $\mathrm{ZnAl}_{2} \mathrm{O}_{4}$ was achieved by Nascimento et al., who subsequently registered a boost in photocatalytic activity through metal-chitosan complexation. $\mathrm{ZnAl}_{2} \mathrm{O}_{4}$ exhibited heightened photocatalytic efficacy, which rose from $15 \%$ in the case of pure samples to as much as $64 \%$ to $83 \%$ in the case of the adapted samples when subjected to ultraviolet irradiation, as revealed when substituted by $\mathrm{Co}^{2+}$ and $\mathrm{Ni}^{2+}$ ions. Instead of giving the concentration ratios for $\mathrm{Co}^{2+}$ and $\mathrm{Ni}^{2+}$, however, the literature concentrates primarily on rhodamine $\mathrm{B}$ photodegradation [21]. In the case of trivalent ionsubstituted zinc aluminate, Sumathi et al. found that the existence of a very small concentration of additive $\mathrm{Ce}^{3+}$ ions $(0.01 \mathrm{~mol} \%)$ in the $\mathrm{ZnAl}_{2} \mathrm{O}_{4}$ sample caused an enormous decrease in $E_{g}$ from $3.79 \mathrm{eV}$ to $3.02 \mathrm{eV}$. The photocatalytic performance of $\mathrm{Ce}^{3+}$-doped $\mathrm{ZnAl}_{2} \mathrm{O}_{4}$ on the degradation of methylene blue and methyl orange was very high when using UV-light irradiation, with the decomposition of $94 \%$ achieved within only a 5-minute period. However, the study limited the $\mathrm{Ce}^{3+}$ concentration in the research up to a maximum of $0.03 \mathrm{~mol} \%\left(\mathrm{ZnAl}_{2-\mathrm{x}} \mathrm{Ce}_{\mathrm{x}} \mathrm{O}_{4}\right.$ where $x=0.01$, 0.02 , and 0.03) [22]. An analogous result was found by Kirankumar et al., whose bismuth-doped zinc aluminate nanoparticles with a composition of $\mathrm{ZnAl}_{2-\mathrm{x}} \mathrm{Bi}_{\mathrm{x}} \mathrm{O}_{4}(x=0,0.05$, 0.1) were synthesized using the co-precipitation method. The sample with a very low $\mathrm{Bi}^{3+}$ concentration of $0.05 \mathrm{~mol} \%\left(\mathrm{ZnAl}_{1.95} \mathrm{Bi}_{0.05} \mathrm{O}_{4}\right)$ showed an extreme decrease in $E_{g}$ from $4.59 \mathrm{eV}$ of the pure sample to $3.50 \mathrm{eV}$. They found that a co-doped sample with $0.10 \mathrm{~mol} \%$ of $\mathrm{Bi}^{3+}$ ions showed $\mathrm{MB}$ degradation efficiency at about $70 \%$ in 30 min before reaching a maximum value of $99 \%$ within 4 h. Similarly, they limited the $\mathrm{Bi}^{3+}$ concentration in their work to a maximum of $0.1 \mathrm{~mol} \%$ [23]. Thus, the results of the current work show that both divalent and trivalent transition metal seemed to be a significant factor in the considerable decrease of $E_{g}$ with tremendously enhanced photocatalytic activity for modified $\mathrm{ZnAl}_{2} \mathrm{O}_{4}$ powders. Furthermore, it has not yet been possible to establish the difference in $\mathrm{Eg}$ and photocatalytic behavior concerning the organic contaminants of $\mathrm{ZnAl}_{2} \mathrm{O}_{4}$ altered using various concentrations of trivalent $\mathrm{Fe}^{3+}$ ions. There are also numerous differences in the scientific information that needs further study and appraisal.

The sol-gel auto combustion method was used in the present work to formulate a sequence of nanocrystalline $\mathrm{ZnFe}_{\mathrm{x}} \mathrm{Al}_{2-\mathrm{x}} \mathrm{O}_{4}$ powders with varying $\mathrm{Fe}^{3+}$ ion concentrations $(x=0,0.5,1,1.5$, and 2). Structures, chemical bonds, morphologies, composition, surface area, and optical characteristics, including the magnetic behaviors of the powders collected, were analyzed by Xray diffraction (XRD), Fourier transform infrared spectroscopy (FT-IR), and electron scanning microscopy (SEM), as well as energy dispersive spectroscopy (EDS), the Brunauer-Emmett-Teller (BET) approach, and UV-visible diffuse reflective spectroscopic spectroscopy. To evaluate the photocatalytic degradation characteristics of the aluminate spinel powders to assess their efficacy in the treatment of wastewater, experiments were performed on a number of different organic compounds, thus enabling comparisons to be made between the various molecular structures. Sunlight irradiation was used for experiments to decompose the organic compounds, phenol rhodamine $\mathrm{B}(\mathrm{RhB})$, heteropolyaromatic methylene blue (MB), azoic methyl orange (MO), and 
methyl red (MR). The different catalytic capabilities were analyzed and the related photocatalytic processes will be clarified.

\section{Experiments}

\subsection{Materials}

To synthesize the iron-substituted zinc aluminates at differing $\mathrm{Fe}^{3+}$ ion concentrations, various materials were needed, all of which were acquired from Ajax Finechem and were of analytical grade, meaning they could be utilized without supplementary purification. $\mathrm{Zn}\left(\mathrm{NO}_{3}\right)_{2} \bullet 6 \mathrm{H}_{2} \mathrm{O}$ (zinc nitrate hexahydrate), iron (III) nitrate nonahydrate $\left(\mathrm{Fe}\left(\mathrm{NO}_{3}\right)_{3} \cdot 9 \mathrm{H}_{2} \mathrm{O}\right), \mathrm{Al}\left(\mathrm{NO}_{3}\right)_{3} \bullet 9 \mathrm{H}_{2} \mathrm{O}$ (aluminium nitrate nonahydrate), and $\mathrm{C}_{4} \mathrm{H}_{11} \mathrm{NO}_{2}$ (diethanolamine; DEA). Rhodamine $\mathrm{B}\left(\mathrm{RhB}, \mathrm{C}_{28} \mathrm{H}_{31} \mathrm{ClN}_{2} \mathrm{O}_{3}\right.$ ), methylene blue $\left(\mathrm{MB}, \mathrm{C}_{16} \mathrm{H}_{18} \mathrm{ClN}_{3} \mathrm{~S} \cdot 2 \mathrm{H}_{2} \mathrm{O}\right)$, methyl orange $\left(\mathrm{MO}, \mathrm{C}_{14} \mathrm{H}_{14} \mathrm{~N}_{3} \mathrm{SO}_{3} \mathrm{Na}\right)$, and methyl red (MR, $\mathrm{C}_{15} \mathrm{H}_{15} \mathrm{~N}_{3} \mathrm{O}_{2}$ ) were included on the list of analytical grade materials acquired from Loba Chemie, Ajax Finechem, and PanReac AppliChem.

\subsection{Preparation of iron-substituted zinc aluminate powders}

The sol-gel auto combustion process was used to synthesize various iron-substituted zinc aluminate powders, with a series of $\mathrm{ZnFe}_{\mathrm{x}} \mathrm{Al}_{2-\mathrm{x}} \mathrm{O}_{4}$ powders of varying trivalent ion concentrations resulting to specify values for $x$ of $0,0.5,1,1.5$, and 2 . The operation started with the development of a $0.2 \mathrm{~mol} / \mathrm{L}$ absolute ethanol solution comprising metal nitrates and aluminum nitrate at the necessary amounts. DEA fuel was used with an equivalence ratio $\left(\Phi_{\mathrm{e}}\right)$ of the oxidizer to the fuel. Diethanolamine complexes of metal ions were generated at a temperature of $200^{\circ} \mathrm{C}$ with dehydration observed as well. The creation of dark brown powders resulted after a viscous gel emerged at roughly 40 minutes, with self-ignition after that. Subsequently, the powders were calcined in air at $1000^{\circ} \mathrm{C}$ for 4 hours.

\subsection{Characterizations}

To ascertain the crystalline phase, a Bruker D8 Advance X-ray diffractometer (XRD) coupled with $\mathrm{Ni}$-filtered $\mathrm{Cu} K_{\alpha}$ radiation $\left(\lambda=1.5406 \AA\right.$ ) was employed. With time periods of 1 second and $0.04^{\circ}$ scanning steps, the XRD patterns were acquired in the range of $20^{\circ}$ to $80^{\circ}$. According to the $\mathrm{KBr}$ pellets method, analysis of bonding in the molecules was carried out using the Fourier transform infrared (FT-IR) spectra of the samples calculated on a Thermo scientific infrared spectrometer (Nicolet 6700) in a range of 400-4000 $\mathrm{cm}^{-1}$. A quanta 450 FEI scanning electron microscope (SEM) fitted with an energy dispersion spectrometer (EDS, Oxford Instrument X-Max $50 \mathrm{~mm}^{2}$ detector) was used to describe the morphologies and chemical characteristics of the specimens. The surface area of the powders was analyzed by means of a nitrogen physisorption examination (Micromeritics 3Flex) using the Brunauer-Emmett-Teller (BET) technique. The samples were degassed in a vacuum at $300^{\circ} \mathrm{C}$ for 12 hours (overnight) before experimentation. An Agilent Cary $5000 \mathrm{UV}-\mathrm{Vis}$ NIR spectrometer with an integrated diffuse reflectance accessory in the wavelength ranges of 200-2000 $\mathrm{nm}$ was used to report the UV-visible diffuse reflectance spectra (UV-DRS) to ascertain the energy bandgap for all aluminate samples. A vibrating sample magnetometer 
(VSM, LakeShore Model 7404) with an exterior field range of $\pm 12 \mathrm{kOe}$ was used to test the magnetic characteristics of pure and substituted samples at room temperature.

\subsection{Photocatalytic activity and organic dye degradation experiments}

With measurements gained using an absorption-based spectroscopic approach, the photodegradation of the pollutants $\mathrm{RhB}, \mathrm{MB}, \mathrm{MO}$, and $\mathrm{MR}$ using $\mathrm{ZnFe}_{\mathrm{x}} \mathrm{Al}_{2-\mathrm{x}} \mathrm{O}_{4}$ powders was assessed under experimental sunlight irradiation conditions. At a preliminary concentration of 10 $\mathrm{mg} / \mathrm{L}$ in a $50 \mathrm{~mL}$ aqueous solution, beakers were arranged to hold dyes of $\mathrm{RhB}, \mathrm{MB}, \mathrm{MO}, \mathrm{MR}$. Subsequently, a small quantity of $0.01 \mathrm{~g}$ of the powdered catalyst was added. The solution was agitated in darkness for 30 minutes to confirm acceptable adsorption-desorption equilibrium between the dye molecules and the photocatalyst surface. The solution was then placed in direct sunlight for six hours on two successive days in June 2020 from 9 a.m. to 3 p.m. to facilitate photocatalysis. At 30-minute periods, $3 \mathrm{~mL}$ of suspension was extracted and centrifuged at 3,000 rpm for 5 minutes to eliminate the catalyst particles. A UV-visible spectrophotometer was used to measure the dilution of the residual dye. Any decrease in the dilutions was examined at the highest absorption peaks $(554 \mathrm{~nm}, 664 \mathrm{~nm}, 464 \mathrm{~nm}$, and $522 \mathrm{~nm})$. To estimate the percentage of degradation efficiency, the equation below was used:

$\%$ degradation $=\frac{C_{0}-C_{t}}{C_{0}} \times 100$

where $C_{0}$ and $C_{t}$ are the dye concentrations after solution irradiation times of 0 minutes and $t$ minutes, respectively. It was essential to perform a 4-cycle photodegradation experiment for each of the dyes to establish the stability of the produced aluminate powder, with each cycle completion taking around 150 minutes, at which point the sample matured for 30 minutes before diffusion in a new solution for successive cycles once it was cleaned with water three times.

\section{RESULTS \& DISCUSSIONS}

\subsection{Phase identification}

To examine the phase purity of the samples and crystal structure by likening the diffraction angle $2 \theta$ with the standard data from the JCPDS powder diffraction file, evaluation of the structure of the iron-substituted zinc aluminate powders was accomplished with the XRD approach. Figure 1 shows the XRD spectra for the $\mathrm{ZnFe}_{\mathrm{x}} \mathrm{Al}_{2-\mathrm{x}} \mathrm{O}_{4}$ powders, which had fluctuating $\mathrm{Fe}^{3+}$ ion concentrations $(x=0,0.5,1,1.5$, and 2$)$. Each various sample displayed typical diffraction of the (220), (311), (222), (400), (331), (422), (511), (440), (531), (620), and (533) planes at $2 \theta$ of $31^{\circ}$, $37^{\circ}, 38^{\circ}, 45^{\circ}, 49^{\circ}, 56^{\circ}, 59^{\circ}, 65^{\circ}, 69^{\circ}, 74^{\circ}$, and $78^{\circ}$, respectively [24-26]. These findings correlate with the standard data anticipated for $\mathrm{ZnAl}_{2} \mathrm{O}_{4}$ (JCPDS file No. 05-0669) and $\mathrm{ZnFe}_{2} \mathrm{O}_{4}$ (JCPDS file No. 89-1012), signifying the existence of a single-phase cubic spinel construction with the space group $F d \overline{3} m[27,28]$. No secondary phases have been seen in the XRD patterns showing $\mathrm{Al}_{2} \mathrm{O}_{3}, \mathrm{Fe}_{2} \mathrm{O}_{3}$, or $\mathrm{ZnO}$. Therefore, the phase purity of the samples can be inferred [29-31]. It was evident that the calcined samples had been well-crystallized and had a long-range organized 
composition based on the sharp and dominant diffraction peaks for the samples. The results also indicate that there is no dominant influence on the crystallization of the substituting material of $\mathrm{Fe}^{3+}$, whereas the substitution effect of $\mathrm{Fe}^{3+}$ on the crystalline phase may be derived from the diffraction peak change. The direction of both peaks demonstrated a steady left-shift to the lower angle of $2 \theta$ as the concentration of $\mathrm{Fe}^{3+}$ increased from $x=0$ to $x=2$. This shows the diversity in the unit cell dimensions for these specific spinel aluminates [32].

\subsection{Structural analysis}

By using Bragg's equation (2), the strongest diffraction peak (311) could be used to determine the interplanar spacing $\left(d_{h k l}\right)$ for the aluminate samples.

$d_{h k l}=\frac{\lambda}{2 \sin \theta}$

As a result, it was possible to estimate the mean crystallite diameter $(D)$ for the spinel powders using two reliable approaches. The first of these techniques was the Scherrer method,

$$
D_{S C}=\frac{0.9 \lambda}{\beta \cos \theta}
$$

in which $\lambda$ denotes the X-ray source wavelength $\left(\mathrm{Cu} K_{\alpha}=1.54 \AA\right), \beta$ represents the FWHM for the most notable (311) intensity peak, while $\Theta$ indicates the Bragg angle position. The size of the Bragg angle at its peak is dependent upon both the instrument used and the broadening of the sample. This broadening effect must therefore be removed so that the sample can be assessed in isolation using silicon acting as the standard material. The instrumentally-corrected broadening, $\beta$, which matched the sample diffractions peak, could be determined using the relationship described below as:

$\beta=\left[\beta_{\text {measured }}^{2}-\beta_{\text {instrumental }}^{2}\right]^{\frac{1}{2}}$

The alternative method had its basis in the idea that it is possible for synthesized powders to contain microstrains $(\mathcal{E})$ which result from the distortions or imperfections found in the crystals. Microstrain calculation is performed using the formula given below [33]:

$$
\varepsilon=\frac{\beta_{h k l}}{4 \tan \theta}
$$

From Equations (3) and (5) it can be inferred that the peak width which occurs as a result of differing crystallite sizes varies as $1 / \cos \theta$ whereas the strain varies as $\tan \theta$. The overall peak broadening can be given by the sum of the crystallite size and strain in the material, which is expressed as:

$$
\beta_{h k l}=\beta_{D}+\beta_{\varepsilon}
$$


where $\beta_{D}$ stems from the effects of crystallite size, $\beta_{\varepsilon}$ is the consequence of broadening caused by the strain, while $\beta_{h k l}$ indicates the breadth of the half-maximum intensity of the instrumentallycorrected broadening [34]. On the basis that particle size and strain will have independent effects on line broadening, presenting a Cauchy-like profile, the sum of Equations (2) and (4) will determine the line breadth, and can be expressed as:

$$
\beta_{h k l}=\frac{K \lambda}{D_{W H} \cos \theta}+4 \varepsilon \tan \theta
$$

By rearranging this equation.

$$
\beta_{h k l} \cos \theta=\frac{K \lambda}{D_{W H}}+4 \varepsilon \sin \theta
$$

Equations (7) and (8) which are presented above are the Williamson-Hall (W-H) equations [33, 34]. For a Williamson-Hall analysis to be carried out, a plot must first of all be created where the $x$-axis denotes $4 \sin \theta$ and the $y$-axis represents $\beta_{h k l} \cos \theta$ in order that each of the dominant orientation peaks are displayed for the spinel aluminate powders. Figure 2 presents this scenario. This technique is called the size-strain plot (SSP). By considering linear data, it was possible to obtain a crystallite size $\left(D_{W H}\right)$ estimate using the $y$-intercept and microstrain $(\varepsilon)$ on the basis of the gradient of the fit [35]. Table 1 shows a summarized version of the calculated findings of $\mathrm{d}_{311}, D_{S C}$ and $D_{W H}$ obtained from Bragg, Scherrer, and Williamson-Hall equations. When the $D_{S C}$ and the $D_{W H}$ values are in agreement, this serves as confirmation of the creation of nanocrystalline aluminate samples of diameter from $40 \mathrm{~nm}$ to $50 \mathrm{~nm}$ in all cases. Each of the $\varepsilon$ values (taken from the linear equation gradient value in Figure 2) which approaches zero shows that the value of the microstrain in the substance is small enough to be safely ignored.

\subsection{Chemical bonding analysis}

Fourier transform infrared spectroscopy (FT-IR) can be used to assess the surface functional groups and the elaboration of spinel structures. Figure 3, including reports from the range of 400$4000 \mathrm{~cm}^{-1}$, shows the FT-IR spectra for calcined $\mathrm{ZnFe}_{\mathrm{x}} \mathrm{Al}_{2-\mathrm{x}} \mathrm{O}_{4}$ powders. Characteristic of these calcined samples is the development of FT-IR spectra, which involves poor absorption bands about 3448, 2922, 2851, 2442, 1637, 1551, 1419 and $858 \mathrm{~cm}^{-1}$. Among the bands, the 3448, 1637, and $1551 \mathrm{~cm}^{-1}$ bands can be assigned to the hydroxyl group, which demonstrates both symmetrical and anti-symmetrical bending and vibrational stretching patterns as a result of diffusing moisture from the atmosphere into the samples while the $\mathrm{KBr}$ pellets undergo readiness [36]. Simultaneously, the C-H extending vibrational modes can explain the minor peaks at around 2922 and $2851 \mathrm{~cm}^{-1}$, while the absorption band logged at $2442 \mathrm{~cm}^{-1}$ may result from carbon dioxide in the air and the samples $[37,38]$. The symmetrical bending and expanding modes of the $\mathrm{C}-\mathrm{O}$ group, which is part of the

$\mathrm{CO}_{3}{ }^{2-}$ molecules, are liable for the band seen at $858 \mathrm{~cm}^{-1}$, while another small peak reported at 1419 
$\mathrm{cm}^{-1}$ originates from the presence of residual nitrogen groups produced as a result of the combustion reaction $[39,40]$. It is characteristic of vibrational frequencies for aluminum spinel structures to come within a band of $400 \mathrm{~cm}^{-1}$ to $800 \mathrm{~cm}^{-1}$. The detected bands are the product of three distinct modes of $\mathrm{M}-\mathrm{O}, \mathrm{Al}-\mathrm{O}$, and $\mathrm{M}-\mathrm{O}-\mathrm{Al}$ bonds found at the tetrahedral and octahedral sites of metal aluminate spinels $\left(\mathrm{MAl}_{2} \mathrm{O}_{4}\right.$ in which the metal, $\mathrm{M}$, can be zinc and iron) [41]. The three modes are symmetrical stretching $\left(v_{1}\right)$, folding $\left(v_{2}\right)$, and asymmetrical stretching $\left(v_{3}\right)$. Upon analysis through the FT-IR spectrum, non-substituted samples, where $x=0$, show a crystallization step for the $\mathrm{ZnAl}_{2} \mathrm{O}_{4}$ aluminum spinel with strong bands occurring at 660,554 , and $495 \mathrm{~cm}^{-1}$, showing the vibrations of the $\mathrm{Zn}-\mathrm{O}$ tetrahedral bonds $\left[\mathrm{Zn}^{2+} \mathrm{O}_{4}\right]$, the $\mathrm{Zn}-\mathrm{O}-\mathrm{Al}$ bonds within the spinel structure, and the Al-O octahedral bonds $\left[\mathrm{Al}^{3+} \mathrm{O}_{6}\right]$ [42]. It could be concluded that the produced $\mathrm{ZnAl}_{2} \mathrm{O}_{4}$ sample has a normal spinel structure, as there is no reported vibration of approximately $700 \mathrm{~cm}^{-1}$ to $800 \mathrm{~cm}^{-1}$, which would indicate that $\mathrm{Al}-\mathrm{O}$ interaction $\left[\mathrm{Al}^{3+} \mathrm{O}_{4}\right]$ is taking place at tetrahedral sites [43]. It can be shown that the absorption band of all $\mathrm{Fe}^{3+}$-substituted $\mathrm{ZnAl}_{2} \mathrm{O}_{4}$ samples changes significantly to a reduced wavenumber value with a large variance in the absorption rate. This incidence may result from the $\mathrm{Fe}^{3+}$ having a larger ion radius $(0.65 \AA)$ than $\mathrm{Al}^{3+}$ ion $(0.54 \AA)$. Certain $\mathrm{Zn}^{2+}$ ions with comparable ion radius ( $0.60 \AA$ ) from the tetrahedral site to the octahedral site can be occupied and directed if the concentration of $\mathrm{Fe}^{3+}$ climbs [44]. In contrast, the extended bond length of Fe-O can move and influence the absorption efficiency proportionate to the Al-O bond [28]. The lowest band is immensely shifted to the lower value at about $400 \mathrm{~cm}^{-1}$ when $\mathrm{Al}^{3+}$ ions are substituted by $\mathrm{Fe}^{3+}$ ions $(x=2)$, though the new highest band emerges apparently at $678 \mathrm{~cm}^{-1}$. The presence of the lowest band accounts for the unique manifestation of the highest values logged for aluminum or iron ions observed at the tetrahedral sites $\left[\mathrm{Al}^{3+} \mathrm{O}_{4}\right.$ or $\left.\mathrm{Fe}^{3+} \mathrm{O}_{4}\right]$, as well as for zinc ions at the octahedral sites $\left[\mathrm{Zn}^{2+} \mathrm{O}_{6}\right]$ [45-48]. The recurrent addition of $\mathrm{Fe}^{3+}$ ions causes the measured revolution of crystal lattice from a normal structure to a reversed spinel, as revealed by the results [49]. As established by XRD results, the FT-IR spectra display no other indications of contaminants.

\subsection{Surface texture, morphological, and chemical composition analysis}

The results of scanning electron microscopy (SEM) analysis for the assessment of surface morphology and particle size of iron-substituted zinc aluminate spinel powders are given in Figure 4. Particle accretion as a result of the combustion and calcination processes happening at high temperature is shown in the SEM. The presence of magnetostatic interactions that occur between particles may be another reason for the aggregation. The pure $\mathrm{ZnAl}_{2} \mathrm{O}_{4}$ particles are observed in a spherical shape with a mean size of $50 \mathrm{~nm}$, as seen in Figure $4 \mathrm{a}$. The structure of the $\mathrm{ZnFe}_{\mathrm{x}} \mathrm{Al}_{2-\mathrm{x}} \mathrm{O}_{4}$ samples progresses. For a sample with low supplementary ion concentrations $(x=0.5)$ such as $\mathrm{ZnFe}_{0.5} \mathrm{Al}_{1.5} \mathrm{O}_{4}$ (Fig. 4b), the shape of the particle varies from a normal spherical form to a polyhedron, while at the same time rising in size to a maximum of $200 \mathrm{~nm}-500 \mathrm{~nm}$. Conversely, the structure may assume a variety of appearances when these two trivalent ions are evenly sorted, as in the case of the $\mathrm{ZnFeAlO}_{4}$ sample (Fig. 4c), such as triangles, hexagons, other polyhedrons and irregular shapes. This concludes the homogeneous distribution as particle size grows from 400 
$\mathrm{nm}$ to $1000 \mathrm{~nm}$. In comparison, an additional increase in the concentration of $\mathrm{Fe}^{3+}(x=1.5$ and 2) corresponds to an increase in the size of the particle. In $\mathrm{ZnFe}_{1.5} \mathrm{Al}_{0.5} \mathrm{O}_{4}$ (Fig. 4d) and $\mathrm{ZnFe}_{2} \mathrm{O}_{4}$ (Fig. 4e), the samples revert mostly to the shape of a stacked polyhedron, while at the same time growing significantly to the scale of $1000 \mathrm{~nm}-1500 \mathrm{~nm}$. Besides, pores can be formed in iron-substituted zinc aluminate spinel powders as the combustion reaction leads to the emission of volatile gases, such as carbon dioxide, nitrogen, oxygen, and steam. Thus, when catalytic action is needed, the ensuing pore structure and its linking ties can play a key role.

Energy dispersive spectroscopy (EDS) was the approach used to assess the chemical content of the samples that were produced. Conceivably, every element could be recognized in the ironsubstituted zinc aluminate powders. The results from this examination are shown in the insets inside Figure 4. In Table 2, the EDS spectra exhibited no impurity peaks, while the quantitative study results can be perceived. To provide a mean value, three measurements were gained for each of the aluminate samples. The registered element stoichiometry for these samples roughly met the theoretical expectancies.

As shown with the findings offered in Table 3, the Brunauer-Emmett-Teller (BET) approach was used to examine the surface area $\left(S_{B E T}\right)$ of both pure and substituted zinc aluminate spinel powders. Pure $\mathrm{ZnAl}_{2} \mathrm{O}_{4}$ has a surface area of $8.1 \mathrm{~m}^{2} \cdot \mathrm{g}^{-1}$. Still, these $S_{B E T}$ values of $\mathrm{ZnFe}_{\mathrm{x}} \mathrm{Al}_{2-\mathrm{x}} \mathrm{O}_{4}$ powders diminish continually with rising $\mathrm{Fe}^{3+}$ content. $\mathrm{ZnFe}_{\mathrm{x}} \mathrm{Al}_{2-\mathrm{x}} \mathrm{O}_{4}$ powders coupled with $\mathrm{Al}^{3+}$ and $\mathrm{Fe}^{3+}$ ions $(0.5 \leq x \leq 1.5)$ have been found to have a subsidence region of $6.3 \mathrm{~m}^{2} \cdot \mathrm{g}^{-1}$ to $2.2 \mathrm{~m}^{2} \cdot \mathrm{g}^{-1}$. In the event that the $\mathrm{Al}^{3+}$ ions were completely replaced by $\mathrm{Fe}^{3+}$ ions $(x=2)$, the result was a clear reduction in the surface area to a level of $1.4 \mathrm{~m}^{2} \cdot \mathrm{g}^{-1}$. The lower surface area reported may be explainable by larger particle size and crystal size shown in both SEM and XRD data.

\subsection{Optical properties analysis}

UV-visible diffuse reflectance spectroscopy (UV-DRS) was used to establish the optical properties and electronic configurations of the semiconductor nanocrystals. Figure 5 provides the findings for variable additional ion concentrations and shows the UV-DRS spectra for the nanocrystalline iron-substituted zinc aluminate spinel powders. The transfer of electrons from the valence band to the conduction band facilitates the detection of the absorption band. The pure sample of $\mathrm{ZnAl}_{2} \mathrm{O}_{4}$ shows clear reflectance across the spectral range for both the VIS and NIR regions at $500 \mathrm{~nm}$ to $1000 \mathrm{~nm}$, with a reflectance of approximately 90-96\%, as the evidence shows in Figure 5. The absorption band provides 50-85\% reflectance values from about $200 \mathrm{~nm}$ to $400 \mathrm{~nm}$ throughout the UV region. The $\mathrm{ZnAl}_{2} \mathrm{O}_{4}$ aluminum spinel has high-energy bands at $240 \mathrm{~nm}$ and $260 \mathrm{~nm}$, consistent with electron excitation on a band-to-band basis between loaded $2 p$ oxygen orbitals and empty $3 s$ aluminum orbitals, though there is a possibility for $3 p$ wave function mixing in aluminum [50]. At the same time, there is a shoulder in the $320 \mathrm{~nm}$ to $350 \mathrm{~nm}$ wavelength region that comes from the transfer of electrons between filled $2 p$ orbitals of oxygen and empty $4 s$ orbitals of zinc. This will depend on the spinel defects [51]. The structure endures substantial modification in the case of $\mathrm{ZnFe}_{\mathrm{x}} \mathrm{Al}_{2-\mathrm{x}} \mathrm{O}_{4}$ powders with low added ion concentrations $(x=0.5)$ as shown for 
$\mathrm{ZnFe}_{0.5} \mathrm{Al}_{1.5} \mathrm{O}_{4}$, resulting in the presence of three new absorption bands at 460, 800, and $1300 \mathrm{~nm}$ with the parallel reinforcement of the UV and VIS absorption bands. The absorption bands shown by the Fe-substituted $\mathrm{ZnAl}_{2} \mathrm{O}_{4}$ sample at UV to NIR wavelengths derive from electronic transfers within the $3 d^{5}$ shell of the $\mathrm{Fe}^{3+}$ cation [52]. The cause for the higher absorption band in the UV region, which occurs below $400 \mathrm{~nm}$, is the excitation of electrons from ${ }^{6} \mathrm{~A}_{1}\left({ }^{6} \mathrm{~S}\right)$ to ${ }^{4} \mathrm{E} ;{ }^{4} \mathrm{~A}_{1}$. Also, there is a low VIS band in the region of $460-550 \mathrm{~nm}$, which can be clarified by the transition of charges from $2\left({ }^{6} \mathrm{~A}_{1}\right)$ to $2\left({ }^{4} \mathrm{~T}_{1}\right)$. Concurrently, the additional bands located at around $800 \mathrm{~nm}$ are the product of the ${ }^{6} \mathrm{~A}_{1} \rightarrow{ }^{4} \mathrm{~T}_{2}$ transition. The presence of a novel absorption band in the NIR region between 900 and $1400 \mathrm{~nm}$ can be attributed to the electronic transition between ${ }^{6} \mathrm{~A}_{1} \rightarrow{ }^{4} \mathrm{~T}_{1}$ [53]. The reflectance of VIS and NIR regions for all iron-substituted zinc-aluminum samples decreases steadily as $\mathrm{Fe}^{3+}$ ions increase, whereas that of the UV region stays constant. The lowest values were registered at $11 \%$ for the UV region, $10 \%$ for the VIS region, and $22 \%$ for the NIR region.

\subsection{Energy band gap analysis}

As presented in Equations (9) and (10), the optical band gaps of all samples were established from UV-DRS spectra by using the Kubelka-Munk function and Tauc relation, respectively [54].

$$
\alpha=F(R)=\frac{(1-R)^{2}}{2 R}
$$

where $F(R)$ is the Kubelka-Munk function, $\alpha$ is the absorption coefficient, and $R$ is the reflectance.

$$
F(R) h v=A\left(h v-E_{g}\right)^{n}
$$

where $h v$ is light energy, $A$ is constant, $E_{g}$ is bandgap energy, and $n=1 / 2$ for direct bandgap.

A plot of $(F(R) h v)^{2}$ contrasted with $h v$ for all iron-substituted zinc aluminate spinel specimens is shown in Figure 6. The junctures of the extrapolation of Tauc plots and the $h v$-axis comprise the direct bandgap value $\left(E_{g}\right)$. The direct bandgap for the prepared $\mathrm{ZnAl}_{2} \mathrm{O}_{4}$ where $x=0$ was $5.60 \mathrm{eV}$, reflecting a small improvement over the gained value of $5.1 \mathrm{eV}$ when urea was used as a fuel [20]. This optical band gap change can occur as a consequence of the various particle sizes and distributions contributing to a failure of uniformity in the expansion of the optical spectra [55]. The results indicate substantial reductions in bandgap quantities for all replacement zinc-aluminum samples as a result of $\mathrm{Fe}^{3+}$ ions, which were observed in comparison to pure samples. These findings are summarized in Table 3. For samples of $\mathrm{ZnFe}_{0.5} \mathrm{Al}_{1.5} \mathrm{O}_{4}$ and $\mathrm{ZnFeAlO}_{4}$ containing low $(x=0.5)$ and moderate $(x=1) \mathrm{Fe}^{3+}$ ions, the $E_{g}$ values decreased to $3.14 \mathrm{eV}$. Once the amount of $\mathrm{Fe}^{3+}$ attained a value greater than $\mathrm{Al}^{3+}(x=1.5)$, as is the case with the study of $\mathrm{ZnFe}_{1.5} \mathrm{Al}_{0.5} \mathrm{O}_{4}$, the $E_{g}$ value decreased significantly to $2.08 \mathrm{eV}$. Although the aluminum ions have been entirely replaced by iron ions, such as $x=2$, the $E_{g}$ value is stable with no noticeable difference. These results indicate that iron-substituted samples are best able to absorb any wavelength in the UV 
range up to the center of the visible light spectrum and can thus operate exactly as photocatalysts under solar light.

\subsection{Photocatalytic activity}

The iron-substituted zinc aluminate spinels have been studied with an interest in determining their photocatalytic properties concerning the degradation of organic dyes, RhB, MB, MO, and MR under sunlight conditions. The results were intended to direct the appropriateness of wastewater treatment approaches. During the trial, experiments were conducted at 30-minute intervals with the exclusion of additives, including hydrogen peroxide. Figure 7 summarizes the findings of the experiments in which $\mathrm{RhB}, \mathrm{MB}, \mathrm{MO}$, and $\mathrm{MR}$ were exposed to photocatalysts of $\mathrm{ZnFe}_{\mathrm{x}} \mathrm{Al}_{2-\mathrm{x}} \mathrm{O}_{4}$ at different ion concentrations $(0 \leq x \leq 2)$. As part of the assessment process, the absorption peaks at $554 \mathrm{~nm}, 664 \mathrm{~nm}, 464 \mathrm{~nm}$, and $522 \mathrm{~nm}$ were calculated. The correlation of residual and original concentrations is regarded as the $C / C_{0}$ ratio and can be plotted against time, as seen in Figure 8 , to display the rate of degradation of the organic dyes studied. Under sunlight irradiance, specimens of zinc-aluminum substituted with a high concentration of iron $(x=1.5$ and 2$)$, as in the case of $\mathrm{ZnFe}_{1.5} \mathrm{Al}_{0.5} \mathrm{O}_{4}$ and $\mathrm{ZnFe}_{2} \mathrm{O}_{4}$, demonstrated a photocatalytic performance that was higher than the pure samples of $\mathrm{ZnAl}_{2} \mathrm{O}_{4}$ and zinc aluminate replaced with low iron $(x=0.5$ and 1$)$ as with $\mathrm{ZnFe}_{0.5} \mathrm{Al}_{1.5} \mathrm{O}_{4}$ and $\mathrm{ZnFeAlO}_{4}$, respectively. Performance values for photodegradation by using samples of $\mathrm{ZnFe}_{1.5} \mathrm{Al}_{0.5} \mathrm{O}_{4}$ and $\mathrm{ZnFe}_{2} \mathrm{O}_{4}$ were $97-98 \%$ for $\mathrm{RhB}$, while $88-90 \%$ for the samples $\mathrm{ZnFe}_{0.5} \mathrm{Al}_{1.5} \mathrm{O}_{4}$ and $\mathrm{ZnFeAlO}_{4}$ were registered. Inferior levels of activity were reported for the pure $\mathrm{ZnAl}_{2} \mathrm{O}_{4}$ sample $(71 \%)$. The efficacy findings for photodegradation using the samples $\mathrm{ZnFe}_{1.5} \mathrm{Al}_{0.5} \mathrm{O}_{4}$ and $\mathrm{ZnFe}_{2} \mathrm{O}_{4}$ were between $97-98 \%$ for $\mathrm{MB}$, while the values of $86-87 \%$ for the samples $\mathrm{ZnFe}_{0.5} \mathrm{Al}_{1.5} \mathrm{O}_{4}$ and $\mathrm{ZnFeAlO}_{4}$ were registered. Reduced levels of activity were documented for a pure sample of $\mathrm{ZnAl}_{2} \mathrm{O}_{4}(71 \%)$. For $\mathrm{MO}$, the findings for photodegradation employing the specimens of $\mathrm{ZnFe}_{1.5} \mathrm{Al}_{0.5} \mathrm{O}_{4}$ and $\mathrm{ZnFe}_{2} \mathrm{O}_{4}$ were 94-96\%, while the values of 83$85 \%$ were reported for the specimens of $\mathrm{ZnFe}_{0.5} \mathrm{Al}_{1.5} \mathrm{O}_{4}$ and $\mathrm{ZnFeAlO}_{4}$. Action levels were the lowest recorded for pure $\mathrm{ZnAl}_{2} \mathrm{O}_{4}$ (70\%). The efficacy findings for photodegradation using the specimens $\mathrm{ZnFe}_{1.5} \mathrm{Al}_{0.5} \mathrm{O}_{4}$ and $\mathrm{ZnFe}_{2} \mathrm{O}_{4}$ were 96-97\% for MR, while 89-91\% for the specimens $\mathrm{ZnFe}_{0.5} \mathrm{Al}_{1.5} \mathrm{O}_{4}$ and $\mathrm{ZnFeAlO}_{4}$ were reported. Reduced values for the pure sample of $\mathrm{ZnAl}_{2} \mathrm{O}_{4}$ $(72 \%)$ were recorded. Noticeably, the lowest degradation capacity reported was correlated with the pure $\mathrm{ZnAl}_{2} \mathrm{O}_{4}$ sample for any of the contaminants tested.

The correlation between photodegradation and the duration of irradiation in the context of organic dyes is exhibited in Figure 9. It is obvious that a rise in one variable is coordinated by a rise in the other. The condition may be assessed using the Langmuir-Hinshelwood (L-H) kinetic model, as below [56]:

$$
\ln \frac{C}{C_{0}}=-k t
$$

where the preliminary dye strength is exemplified by $C_{0}$ and the remaining absorptions at allocated times $t$ are provided as $C$. 
The pseudo-first order rate constant $k\left(\mathrm{~min}^{-1}\right)$ is assessed with respect to the degradations of $\mathrm{RhB}$, MB, MO, and MR for each pure or replaced zinc aluminate sample. Table 4 and Figure 10 provide these results. The concentrations are substantially lower for the pure sample of $\mathrm{ZnAl}_{2} \mathrm{O}_{4}(0.0097$ $\left.0.00102 \mathrm{~min}^{-1}\right)$, and the values are lower than those obtained for $\mathrm{ZnFe}_{0.5} \mathrm{Al}_{1.5} \mathrm{O}_{4}(0.0129-0.0182$ min-1), $\mathrm{ZnFeAlO}_{4}\left(0.0141-0.0178 \mathrm{~min}^{-1}\right), \mathrm{ZnFe}_{1.5} \mathrm{Al}_{0.5} \mathrm{O}_{4}\left(0.0196-0.0282 \mathrm{~min}^{-1}\right)$ and $\mathrm{ZnFe}_{2} \mathrm{O}_{4}$ $\left(0.0215-0.0297 \mathrm{~min}^{-1}\right)$. It can be concluded that those containing $\mathrm{Fe}^{3+}$ can produce better performance when compared to the pure sample of $\mathrm{ZnAl}_{2} \mathrm{O}_{4}$ since the constant values rise in the case of these photocatalysts. It should be recognized that the photocatalytic behavior of every ironsubstituted zinc aluminate spinel is greater than that of a pure sample for the degradation of all organic dyes, while $\mathrm{ZnAl}_{2} \mathrm{O}_{4}$ has the maximum specific surface area. As such, it is apparent that the photocatalytic activity of aluminum spinel particles is greatly improved by the variation in band gap energies $\left(E_{g}\right)$.

The $E_{g}$ specifies the light wavelength for photocatalyst materials, which may be absorbed quickly to generate electron-hole pairs with the ability to react with water molecules, oxygen molecules, and hydroxide ions in order to generate hydroxyl radicals $\left(\mathrm{OH}^{\circ}\right)$ and superoxide radical anions ( $\mathrm{O}_{2}^{--}$) [57, 58]. A schematic illustration of this procedure is given in Figure 11. With the existence of organic compounds, both hydroxyl radicals and superoxide radicals are responsive. Therefore, the oxidation procedure can be accomplished, causing the disintegration of chemical contaminants $[13,59]$. The process of photocatalysis for metal alumina under sunlight can be specified as below:

$$
\begin{aligned}
& \mathrm{MAl}_{2} \mathrm{O}_{4} \stackrel{h v}{\longrightarrow} \mathrm{MAl}_{2} \mathrm{O}_{4}\left(e_{\mathrm{CB}}^{-}+h_{\mathrm{VB}}^{+}\right) \\
& h^{+}+\mathrm{H}_{2} \mathrm{O} \rightarrow \mathrm{H}^{+}+\mathrm{OH}^{\bullet} \\
& e^{-}+\mathrm{O}_{2} \rightarrow \mathrm{O}_{2}^{\cdot-}
\end{aligned}
$$

\section{$\mathrm{RhB} / \mathrm{MB} / \mathrm{MO} / \mathrm{MR}+\left\{\mathrm{O}_{2}^{\bullet-}, \mathrm{OH}^{\bullet}\right\} \rightarrow$ deg raded products}

When evaluating the pure samples of $\mathrm{ZnAl}_{2} \mathrm{O}_{4}$ against the modified samples, a substantial disparity was noted for the $E_{g}$ values, which was identified as impacting the potential for sunlight absorption. In the case of pure samples of $\mathrm{ZnAl}_{2} \mathrm{O}_{4}$, the value for $E_{g}$ was fairly extensive at $5.60 \mathrm{eV}$ with absorbance for only UV-light. As illustrated in Figure 11a, the wavelength did not surpass $221 \mathrm{~nm}$, initiating electron excitation from the valence band to the conduction band. Thus, this specific material offers the poorest performance in terms of photocatalytic degradation. Conversely, Ironexchanged zinc-aluminum samples display significantly reduced values for $E_{g}$ and are capable of absorbing a much broader spectrum of wavelengths from the UV region up to the preliminary $(\sim 400 \mathrm{~nm})$ and intermediate $(\sim 600 \mathrm{~nm})$ phases of the visible sunlight region, as was the case with the test conditions utilized. It is also possible for Fe-substituted $\mathrm{ZnAl}_{2} \mathrm{O}_{4}$ samples to efficiently generate electron-hole pairs capable of offering a high degree of efficacy for photocatalytic degradation. 


\subsection{Reusability analysis}

Because it will impact its practical appropriateness, it is also essential to deliberate the extent to which a photocatalyst can be reused after assessing its photocatalytic effectiveness. In this study, four successive photocatalytic analyses involving the reutilizing of the $\mathrm{ZnFe}_{1.5} \mathrm{Al}_{0.5} \mathrm{O}_{4}$ photocatalyst to degrade fresh solutions of $\mathrm{RhB}, \mathrm{MB}, \mathrm{MO}$, and $\mathrm{MR}$ were carried out to assess the reusability of zinc aluminate powders substituted by iron. Circumstances of sunlight irradiation have been used and the quantities of the catalyst have been constant for the duration of the experiment. Figure 12 reveals that there was no drop in the photocatalytic capacity of the $\mathrm{ZnFe}_{1.5} \mathrm{Al}_{0.5} \mathrm{O}_{4}$ samples during the four experiments for any of the contaminants. Additionally, Figure 13 displays the corresponding XRD pattern for the recycled $\mathrm{ZnFe}_{1.5} \mathrm{Al}_{0.5} \mathrm{O}_{4}$ samples, which revealed no modifications to the photocatalyst crystal structures after the reactions, which hence established that the synthesized iron-substituted zinc aluminate powders may provide the capacity for repetitive use in organic pollutant degradation.

\subsection{Magnetic behavior analysis}

Figure 14 displays magnetic hysteresis loops, which supply capacities for field-dependent magnetization at room temperature. Employing an alternating magnetic field between $\pm 12 \mathrm{kOe}$, these loops can be formed. A magnetic hysteresis loop is shown for $\mathrm{ZnAl}_{2} \mathrm{O}_{4}, \mathrm{ZnFe}_{0.5} \mathrm{Al}_{1.5} \mathrm{O}_{4}$, and $\mathrm{ZnFe}_{1.5} \mathrm{Al}_{0.5} \mathrm{O}_{4}$ spinel samples in Figure 14a. For non-substituted zinc aluminate samples, where $x$ $=0$, the diamagnetic activity in a straight line was observed in $\mathrm{ZnAl}_{2} \mathrm{O}_{4}$. No saturation was detected before $\pm 12 \mathrm{kOe}$. The magnetization was amplified at $0.12 \mathrm{emu} / \mathrm{g}$. These findings are consistent with earlier studies by Anand et al. [19] Any of the spinel aluminates that had been replaced by $\mathrm{Fe}^{3+}$ had a magnetization curve in an S-shape, implying that the substance at issue was ferrimagnetic [60]. Magnetization values $(M)$ have been found to increase as the number of $\mathrm{Fe}^{3+}$ ions increased. The $\mathrm{ZnFe}_{0.5} \mathrm{Al}_{1.5} \mathrm{O}_{4}$ assay displayed improved magnetization at $0.75 \mathrm{emu} / \mathrm{g}$ in samples where the amount of $\mathrm{Fe}^{3+}$ was low $(x=0.5)$. Conversely, the magnetization of $\mathrm{ZnFe}_{1.5} \mathrm{Al}_{0.5} \mathrm{O}_{4}$ increases significantly to $5.8 \mathrm{emu} / \mathrm{g}$ as the amount of $\mathrm{Fe}^{3+}$ ions increases to $x=1.5$. This could be due to the configurations of the magnetic $\mathrm{Fe}^{3+}$ ions at the tetrahedral $(A)$ sites and the octahedral $(B)$ locations, producing $A-B$ inter-sub-lattice super-exchanges that surpass $A$ - $A$ and $B-B$ intra-sub-lattice interactions in terms of performance [61, 62]. Figure 14b indicates the enhancement of the external applied magnetic field within a maximum of \pm 300 Oe for improved observation of certain inherent magnetic features including remanent magnetization $\left(M_{r}\right)$ and coercivity $\left(H_{c}\right)$. The $H_{c}$ value of the pure $\mathrm{ZnAl}_{2} \mathrm{O}_{4}$ sample is $161 \mathrm{Oe}$, while the $\mathrm{ZnFe}_{0.5} \mathrm{Al}_{1.5} \mathrm{O}_{4}$ and $\mathrm{ZnFe}_{1.5} \mathrm{Al}_{0.5} \mathrm{O}_{4}$ samples are $150 \mathrm{Oe}$ and $141 \mathrm{Oe}$, respectively. The transition of the values of $M_{r}$ can be shown clearly by replacing the ions of $\mathrm{Zn}^{2+}$ with the ions of $\mathrm{Fe}^{3+}$. While the pure $\mathrm{ZnAl}_{2} \mathrm{O}_{4}$ and $\mathrm{ZnFe}_{0.5} \mathrm{Al}_{1.5} \mathrm{O}_{4}$ samples had $M_{r}$ values at 0.0015 and $0.1 \mathrm{emu} / \mathrm{g}$, the $\mathrm{ZnFe}_{1.5} \mathrm{Al}_{0.5} \mathrm{O}_{4}$ sample displayed a tremendous boost in retentivity up to $1.73 \mathrm{emu} / \mathrm{g}$. It could be inferred from this information that it would be easy to use an external magnetic field approach to retrieve these adapted magnetic photocatalysts from the reaction system. 
Figure 15 illustrates images of the adapted aluminate photocatalyst. The spinel powders under the magnetic field are observable at the conclusion of the photocatalysis reaction. It can be concluded from this that the magnetic photocatalyst can be retrieved by using an external magnetic field to separate it from the solution.

\section{Conclusions}

A sequence of $\mathrm{ZnFe}_{\mathrm{x}} \mathrm{Al}_{2-\mathrm{x}} \mathrm{O}_{4}$ powders with diverse amounts of $\mathrm{Fe}^{3+}$ ions $(x=0,0.5,1,1.5$, and 2$)$ were effectively prepared in this study using the sol-gel auto combustion method. The findings reveal that the $\mathrm{Fe}^{3+}$ ions were effectively replaced by the crystal lattice $\mathrm{ZnAl}_{2} \mathrm{O}_{4}$. The presence of $\mathrm{Fe}^{3+}$ ions directly affects the composition, morphologies, magnetism, and optical characteristics, including the photocatalytic efficiency of the replaced aluminum samples. By the degradation of $\mathrm{RhB}, \mathrm{MB}, \mathrm{MO}$, and MR at up to $98 \%$ under solar irradiation, the modified aluminum spinels demonstrate higher photocatalytic activity than pure samples. These findings may be credited to intensive absorption through the UV-VIS-NIR regions and a minor energy bandgap. Obviously, pure $\mathrm{ZnAl}_{2} \mathrm{O}_{4}$ spinel powders magnetization was enhanced by boosting the concentration of $\mathrm{Fe}^{3+}$ with a significant increase in the remanent magnetization, which indicates that they can be conveniently retrieved using an external magnetic field. With the aid of magnetic separation, it would also be possible for treating dye wastewater. Moreover, the $\mathrm{Fe}^{3+}$-substituted $\mathrm{ZnAl}_{2} \mathrm{O}_{4}$ photocatalysts reveal elevated stability when reused, which would be beneficial for their real-world use in the photodegradation of biological pollutants from wastewater.

\section{Acknowledgements}

This research was financial supported from the Thailand Research Fund, Office of the Higher Education Commission (Grant number MRG6280220).

\section{References}

[1] Sun Z, Yan Y, Zhang G, Wu Z, Zheng S. The influence of carriers on the structure and photocatalytic activity of $\mathrm{TiO}_{2} /$ diatomite composite photocatalysts. Adv Powder Technol. 2015;26:595-601.

[2] Zong Y, Li Z, Wang X, Ma J, Men Y. Synthesis and high photocatalytic activity of Eu-doped ZnO nanoparticles. Ceram Int. 2014;40:10375-10382.

[3] Cesaro A, Naddeo V, Belgiorno V. Wastewater treatment by combination of advanced oxidation processes and conventional biological systems. J Bioremediat Biodegrad. 2013;4:18.

[4] Gao X, Zhang X, Wang Y, Peng S, Yue B, Fan C. Rapid synthesis of hierarchical BiOCl microspheres for efficient photocatalytic degradation of carbamazepine under simulated solar irradiation. Chem Eng J. 2015;263:419-426.

[5] Payana VG, Lopeza EJH, Laboulais JN, Lopez AL. Parametric sensitivity analysis and ozone mass transfer modeling in a gas-liquid reactor for advanced water treatment. J Ind Eng Chem. 2015;21:1270-1276. 
[6] Zhang Y, Fei L, Jiang X, Pan C, Wang Y. Engineering nanostructured $\mathrm{Bi}_{2} \mathrm{WO}_{6}-\mathrm{TiO}_{2}$ toward effective utilization of natural light in photocatalysis. J Am Ceram Soc. 2011;94:4157-4161.

[7] Chen G, Li D, Li F, Fan Y, Zhao H, Luo Y, Yu R, Meng Q. Ball-milling combined calcination synthesis of $\mathrm{MoS}_{2} / \mathrm{CdS}$ photocatalysts for high photocatalytic $\mathrm{H}_{2}$ evolution activity under visible light irradiation. Appl Catal A-Gen. 2012;443-444:138-144.

[8] Subramanian V, Wolf EE, Kamat PV. Catalysis with $\mathrm{TiO}_{2} /$ Gold nanocomposites. Effect of metal particle size on the Fermi level equilibration. J Am Chem Soc. 2004;126:4943-4950.

[9] Wang S, Guan BY, Lu Y, Lou XWD. Formation of hierarchical $\operatorname{In}_{2} \mathrm{~S}_{3}-\mathrm{CdIn}_{2} \mathrm{~S}_{4}$ heterostructured nanotubes for efficient and stable visible light $\mathrm{CO}_{2}$ reduction. $\mathrm{J}$ Am Chem Soc. 2017;139:17305-17308.

[10] Kamat PV. Photophysical, photochemical and photocatalytic aspects of metal nanoparticles. J Phys Chem B. 2002;106:7729-7744.

[11] Yen CY, Lin YF, Hung CH, Tseng YH, Ma CC, Chang MC, Shao H. The effects of synthesis procedures on the morphology and photocatalytic activity of multi-walled carbon nanotubes/ $/ \mathrm{TiO}_{2}$ nanocomposites. Nanotechnology. 2008;19:045604.

[12] Davar F, Niasari MS. Synthesis and characterization of spinel-type zinc aluminate nanoparticles by a modified sol-gel method using new precursor. J Alloy Compd. 2011;509:2487-2492.

[13] Casbeer E, Sharma VK, Li XZ. Synthesis and photocatalytic activity of ferrites under visible light: A review. Sep Purif Technol. 2012;87:1-14.

[14] Stringhini FM, Foletto EL, Sallet D, Bertuol DA, Filho OC, Nascimento CAO. Synthesis of porous zinc aluminate spinel $\left(\mathrm{ZnAl}_{2} \mathrm{O}_{4}\right)$ by metal-chitosan complexation method. J Alloy Compd. 2014;588:305-309.

[15] Song J, Leng M, Fu X, Liu J. Synthesis and characterization of nanosized zinc aluminate spinel from a novel $\mathrm{Zn}-\mathrm{Al}$ layered double hydroxide precursor. J Alloy Compd. 2012;543:142-146.

[16] Jiang Z, Zhang X, Yuan Z, Chen J, Huang B, Dionysiou DD, Yang G. Enhanced photocatalytic $\mathrm{CO}_{2}$ reduction via the synergistic effect between $\mathrm{Ag}$ and activated carbon in $\mathrm{TiO}_{2} / \mathrm{AC}-\mathrm{Ag}$ ternary composite. Chem Eng J. 2018;348:592-598.

[17] Pelaez M, Nolan NT, Pillai SC, Seery MK, Falaras P, Kontos AG, Dunlop PSM, Hamilton JWJ, Byrne JA, Shea KO, Entezari MH, Dionysiou DD. A review on the visible light active titanium dioxide photocatalysts for environmental applications. Appl Catal B-Environ. 2012;125:331-349.

[18] Anand GT, Kennedy LJ, Vijaya JJ. Microwave combustion synthesis, structural, optical and magnetic properties of $\mathrm{Zn}_{1-\mathrm{x}} \mathrm{Co}_{\mathrm{x}} \mathrm{Al}_{2} \mathrm{O}_{4}(0 \leq \mathrm{x} \leq 0.5)$ spinel nanostructures. J Alloy Compd. 2013;581:558-566.

[19] Anand GT, Kennedy LJ, Vijaya JJ, Kaviyarasan K, Sukumar M. Structural, optical and magnetic characterization of $\mathrm{Zn}_{1-\mathrm{x}} \mathrm{Ni}_{\mathrm{x}} \mathrm{Al}_{2} \mathrm{O}_{4}(0 \leq \mathrm{x} \leq 0.5)$ spinel nanostructures synthesized by microwave combustion technique. Ceram Int. 2015;41:603-615. 
[20] Anand GT, Kennedy LJ, Aruldoss U, Vijaya JJ. Structural, optical and magnetic properties of $\mathrm{Zn}_{1-\mathrm{x}} \mathrm{Mn}_{\mathrm{x}} \mathrm{Al}_{2} \mathrm{O}_{4}(0 \leq \mathrm{x} \leq 0.5)$ spinel nanostructures by one-pot microwave combustion technique. J Mol Struct. 2015;1084:244-253.

[21] Nascimento NMP, Lima BRM, Zamian JR, Costa CEF, Nascimento LAS, Luque R, Filho GNR. Synthesis of Mesoporous $\mathrm{Zn}_{1-\mathrm{x}} \mathrm{M}_{\mathrm{x}} \mathrm{Al}_{2} \mathrm{O}_{4}$ Substituted by $\mathrm{Co}^{2+}$ and $\mathrm{Ni}^{2+}$ Ions and Application in the Photodegradation of Rhodamine B. Materials. 2020;13:2150.

[22] Sumathi S, Kavipriya A. Structural, optical and photocatalytic activity of cerium doped zinc aluminate. Solid State Sci. 2017;65:52-60.

[23] Kirankumar VS, Sumathi S. Catalytic activity of bismuth doped zinc aluminate nanoparticles towards environmental remediation. Mater Res Bull. 2017;93:74-82.

[24] Rogers JL, Mangarella MC, Amico AD, Gallagher JR, Dutzer MR, Stavitski E, Miller JT, Sievers C. Differences in the nature of active sites for methane dry reforming and methane steam reforming over nickel aluminate catalysts. ACS Catal. 2016;6:5873-5886.

[25] Meyer F, Hempelmann R, Mathur S, Veith M. Microemulsion mediated sol-gel synthesis of nano-scaled $\mathrm{MAl}_{2} \mathrm{O}_{4}(\mathrm{M}=\mathrm{Co}, \mathrm{Ni}, \mathrm{Cu})$ spinels from single-source heterobimetallic alkoxide precursors. J Mater Chem. 1999;9:1755-1763

[26] Fabian M, Bottke P, Girman V, Duvel A, Silva KLD, Wikening M, Hahn H, Heitjans P, Sepelak V. A simple and straightforward mechanochemical synthesis of the far-fromequilibrium zinc aluminate, $\mathrm{ZnAl}_{2} \mathrm{O}_{4}$, and its response to thermal treatment. RSC Adv. 2015;5:54321-54328

[27] Van der Laag NJ, Snel MD, Magusin PCMM, With G. Structural, elastic, thermophysical and dielectric properties of zinc aluminate $\left(\mathrm{ZnAl}_{2} \mathrm{O}_{4}\right)$. J Eur Ceram Soc. 2004;24:2417-2424.

[28] Slatineanu T, Iordan AR, Palamaru MN, Caltun OF, Gafton V, Leontie L. Synthesis and characterization of nanocrystalline $\mathrm{Zn}$ ferrites substituted with Ni. Mater Res Bull. 2011;46:1455-1460.

[29] Kong L, Yin X, Ye F, Li Q, Zhang L, Cheng L. Electromagnetic wave absorption properties of $\mathrm{ZnO}$-based materials modified with $\mathrm{Zn}_{2} \mathrm{Al}_{2} \mathrm{O}_{4}$ nanograins. J Phys Chem C. 2013;117:21352146.

[30] Arjmand M, Azad AM, Leion H, Mattisson T, Lyngfelt A. Evaluation of $\mathrm{CuAl}_{2} \mathrm{O}_{4}$ as an oxygen carrier in chemical-looping combustion. Ind Eng Chem Res. 2012;51:13924-13934.

[31] Yang S, Kim K, Baek JI, Kim JW, Lee JB, Ryu CK, Lee G. Spinel Ni(Al,Fe) ${ }_{2} \mathrm{O}_{4}$ solid solution as an oxygen carrier for chemical looping combustion. Energ Fuel. 2012;26:4617-4622.

[32] Carta D, Casula MF, Falqui A, Loche D, Mountjoy G, Sangregorio C, Corrias A. A Structural and Magnetic Investigation of the Inversion Degree in Ferrite Nanocrystals $\mathrm{MFe}_{2} \mathrm{O}_{4}(\mathrm{M}=\mathrm{Mn}$, Co, Ni). J Phys Chem C. 2009;113:8606-8615.

[33] Chittan MV, Kumar CM, Sailaja D, Kumar BR. X-ray peak profile analysis of nanostructured $(\mathrm{ZnO})_{1-\mathrm{x}}(\mathrm{CuO})_{\mathrm{x}}$ composite semiconductor. Mater Today-Proc. 2018;5:21098-21106.

[34] Bindu P, Thomas S. Estimation of lattice strain in $\mathrm{ZnO}$ nanoparticles: X-ray peak profile analysis. J Theor Appl Phys. 2014;8:123-134. 
[35] Hassan M, Younas S, Sher F, Husain SS, Riaz S, Naseem S. Room temperature ferromagnetism in single-phase $\mathrm{Zn}_{1-\mathrm{x}} \mathrm{Mn}_{\mathrm{x}} \mathrm{S}$ diluted magnetic semiconductors fabricated by coprecipitation technique. Appl Phys A-Mater. 2017;123:352.

[36] Ge DL, Fan YJ, Qi CL, Sun ZX. Facile synthesis of highly thermostable mesoporous $\mathrm{ZnAl}_{2} \mathrm{O}_{4}$ with adjustable pore size. J Mater Chem A. 2013;1:1651.

[37] Sharma RK, Ghose R. Synthesis and characterization of nanocrystalline zinc aluminate spinel powder by sol-gel method. Ceram Int. 2014;40:3209-3214.

[38] Wei X, Chen D. Synthesis and characterization of nanosized zinc aluminate spinel by sol-gel technique. Mater Lett. 2006;60:823-827.

[39] Vahur S, Teearu A, Peets P, Joosu L, Leito I. ATR-FT-IR spectral collection of conservation materials in the extended region of 4000-80 $\mathrm{cm}^{-1}$. Anal Bioanal Chem. 2016;408:3373-3379.

[40] Hashemzehi M, Saghatoleslami N, Nayebzadeh H. A study on the structure and catalytic performance of $\mathrm{Zn}_{\mathrm{x}} \mathrm{Cu}_{1-\mathrm{x}} \mathrm{Al}_{2} \mathrm{O}_{4}$ catalysts synthesized by the solution combustion method for the esterification reaction. CR Chim. 2016;19:955-962.

[41] Davar F, Niasari MS. Synthesis and characterization of spinel-type zinc aluminate nanoparticles by a modified sol-gel method using new precursor. J Alloy Compd. 2011;509:2487-2492.

[42] Staszak W, Zawadzki M, Okal J. Solvothermal synthesis and characterization of nanosized zinc aluminate spinel used in iso-butane combustion. J Alloy Compd. 2010;492:500-507.

[43] Grosev VM, Vrankic M, Maksimovic A, Mandic V. Influence of titanium doping on the Raman spectra of nanocrystalline $\mathrm{ZnAl}_{2} \mathrm{O}_{4}$. J Alloy Compd. 2017;697:90-95.

[44] Shannon RD. Revised effective ionic radii and systematic studies of interatomic distances in halides and chalcogenides. Acta Crystallogr A. 1976;32:751-767.

[45] Samkaria R, Sharma V. Effect of rare earth yttrium substitution on the structural, dielectric and electrical properties of nanosized nickel aluminate. Mat Sci Eng B-Adv. 2013;178:14101415.

[46] Buvaneswari G, Aswathy V, Rajakumari R. Comparison of color and optical absorbance properties of divalent ion substituted $\mathrm{Cu}$ and $\mathrm{Zn}$ aluminate spinel oxides synthesized by combustion method towards pigment application. Dyes Pigm. 2015;123:413-419.

[47] Lv W, Luo Z, Yang H, Liu B, Weng W, Liu J. Effect of processing conditions on sonochemical synthesis of nanosized copper aluminate powders. Ultrason Sonochem. 2010;17:344-351.

[48] Niasari MS, Davar F, Farhadi M. Synthesis and characterization of spinel-type $\mathrm{CuAl}_{2} \mathrm{O}_{4}$ nanocrystalline by modified sol-gel method. J Sol-Gel Sci Techn. 2009;51:48-52.

[49] White WB, DeAngelis BA. Interpretation of the vibrational spectra of spinels. Spectrochim Acta A. 1967;23:985-995.

[50] Visinescu D, Jurca B, Ianculescu A, Carp O. Starch - A suitable fuel in new low-temperature combustion-based synthesis of zinc aluminate oxides. Polyhedron. 2011;30:2824-2831. 
[51] Stringhini FM, Foletto EL, Sallet D, Bertuol DA, Filho OC, Nascimento CAO. Synthesis of porous zinc aluminate spinel $\left(\mathrm{ZnAl}_{2} \mathrm{O}_{4}\right)$ by metal-chitosan complexation method. J Alloy Compd. 2014;588:305-309.

[52] Tandon SP, Gupta JP. Diffuse reflectance spectrum of ferric oxide. Spectrosc Lett. 1970;3:297-301.

[53] Scheinost AC, Chavernas A, Barron V, Torrent J. Use and limitations of second-derivative diffuse reflectance spectroscopy in the visible to near-infrared range to identify and quantify Fe oxide minerals in soils. Clays Clay Miner. 1998;46:528-536.

[54] Tauc J, Grigorovici R, Vancu A. Optical properties and electronic structure of amorphous germanium. Phys Status Solidi. 1966;15:627-637.

[55] Ferreira DL, Sousa JCL, Maronesi RN, Bettini J, Schiavon MA, Teixeira AVNC, Silva AG. Size-dependent bandgap and particle size distribution of colloidal semiconductor nanocrystals. J Chem Phys. 2017;147:154102.

[56] Sreelekha N, Subramanyam K, Reddy DA, Murali G, Ramu S, Varma KR, Vijayalakshmi RP. Structural, optical, magnetic and photocatalytic properties of Co doped CuS diluted magnetic semiconductor nanoparticles. Appl Surf Sci. 2016;378:330-340.

[57] Mu HY, Li FT, An XT, Liu RH, Li YL, Qian X, Hu YQ. One-step synthesis, electronic structure, and photocatalytic activity of earth-abundant visible-light-driven $\mathrm{Fe} \mathrm{Al}_{2} \mathrm{O}_{4}$. Phys Chem Chem Phys. 2017;19:9392-9401.

[58] Bharathi P, Harish S, Archana J, Navaneethan M, Ponnusamy S, Muthamizhchelvan C, Shimomura M, Hayakawa Y. Enhanced charge transfer and separation of hierarchical $\mathrm{CuO} / \mathrm{ZnO}$ composites: The synergistic effect of photocatalysis for the mineralization of organic pollutant in water. Appl Surf Sci. 2019;484:884-891.

[59] Bajiri MA, Hezam A, Namratha K, Viswanath R, Drmosh QA, Naik HSB, Byrappa K. $\mathrm{CuO} / \mathrm{ZnO} / \mathrm{g}-\mathrm{C}_{3} \mathrm{~N}_{4}$ heterostructures as efficient visible light-driven photocatalysts. J Environ Chem Eng. 2019;7:103412.

[60] Verde EL, Landi GT, Carrião MS, Drummond AL, Gomes JA, Vieira ED, Sousa MH, Bakuzis AF. Field dependent transition to the non-linear regime in magnetic hyperthermia experiments: Comparison between maghemite, copper, zinc, nickel and cobalt ferrite nanoparticles of similar sizes. AIP Adv. 2012;2:032120.

[61] Anderson HL, Muzquiz MS, Miralles CG, Canevet E, Lock N, Christensen M. Crystalline and magnetic structure-property relationship in spinel ferrite nanoparticles. Nanoscale. 2018;10:14902-14914.

[62] Biasi RS, Santos HF. Cation distribution, saturation magnetization and magneto crystalline anisotropy of mixed ferrite $\mathrm{NiAl}_{x} \mathrm{Fe}_{2-\mathrm{x}} \mathrm{O}_{4}$ nanoparticles. Ceram Int. 2017;43:4557-4561. 


\section{FIGURE CAPTIONS}

Fig. 1 XRD patterns of $\mathrm{ZnFe}_{x} \mathrm{Al}_{2-\mathrm{x}} \mathrm{O}_{4}$ powders with different $\mathrm{Fe}^{3+}$ ion concentrations.

Fig. 2 Plot of $\beta_{h k l} \cos \theta$ versus $4 \sin \theta$ for (a) $\mathrm{ZnAl}_{2} \mathrm{O}_{4}$, (b) $\mathrm{ZnFe}_{0.5} \mathrm{Al}_{1.5} \mathrm{O}_{4}$, (c) $\mathrm{ZnFeAlO}_{4}$, (d) $\mathrm{ZnFe}_{1.5} \mathrm{Al}_{0.5} \mathrm{O}_{4}$, and (e) $\mathrm{ZnFe}_{2} \mathrm{O}_{4}$ powders.

Fig. 3 FT-IR spectra of $\mathrm{ZnFe}_{x} \mathrm{Al}_{2-\mathrm{x}} \mathrm{O}_{4}$ powders with different $\mathrm{Fe}^{3+}$ ion concentrations.

Fig. 4 SEM images and EDS spectra of (a) $\mathrm{ZnAl}_{2} \mathrm{O}_{4}$, (b) $\mathrm{ZnFe}_{0.5} \mathrm{Al}_{1.5} \mathrm{O}_{4}$, (c) $\mathrm{ZnFeAlO}_{4}$, (d) $\mathrm{ZnFe}_{1.5} \mathrm{Al}_{0.5} \mathrm{O}_{4}$, and (e) $\mathrm{ZnFe}_{2} \mathrm{O}_{4}$ powders.

Fig. 5 UV-Visible diffuse reflectance spectra of $\mathrm{ZnFe}_{\mathrm{x}} \mathrm{Al}_{2-\mathrm{x}} \mathrm{O}_{4}$ powders with different $\mathrm{Fe}^{3+}$ ion concentrations.

Fig. 6 Plot of $(F(R) h v)^{2}$ versus $h v$ for $\mathrm{ZnFe}_{x} \mathrm{Al}_{2-\mathrm{x}} \mathrm{O}_{4}$ powders with different $\mathrm{Fe}^{3+}$ ion concentrations.

Fig. 7 UV-Vis absorption spectra for the degradation of (a) RhB, (b) MB, (c) MO, and (d) MR solutions in the presence of $\mathrm{ZnFe}_{\mathrm{x}} \mathrm{Al}_{2-\mathrm{x}} \mathrm{O}_{4}$ powders with different $\mathrm{Fe}^{3+}$ ion concentrations under sunlight irradiation.

Fig. 8 Residual concentration ratio $\left(\mathrm{C} / \mathrm{C}_{0}\right)$ of (a) $\mathrm{RhB}$, (b) $\mathrm{MB}$, (c) $\mathrm{MO}$, and (d) $\mathrm{MR}$ as a function of time under sunlight irradiation for $\mathrm{ZnFe}_{\mathrm{x}} \mathrm{Al}_{2-\mathrm{x}} \mathrm{O}_{4}$ powders with different $\mathrm{Fe}^{3+}$ ion concentrations.

Fig. 9 Kinetic curves of (a) RhB, (b) $\mathrm{MB}$, (c) MO, and (d) MR degradation under sunlight irradiation in the presence of $\mathrm{ZnFe}_{\mathrm{x}} \mathrm{Al}_{2-\mathrm{x}} \mathrm{O}_{4}$ powders with different $\mathrm{Fe}^{3+}$ ion concentrations.

Fig. 10 First order rate constant $k\left(\mathrm{~min}^{-1}\right)$ of $\mathrm{ZnFe}_{x} \mathrm{Al}_{2-\mathrm{x}} \mathrm{O}_{4}$ powders with different $\mathrm{Fe}^{3+}$ ion concentrations for the degradation of $\mathrm{RhB}, \mathrm{MB}, \mathrm{MO}$, and MR.

Fig. 11 Schematic illustration of possible mechanism of (a) pure $\mathrm{ZnAl}_{2} \mathrm{O}_{4}$, (b) $\mathrm{ZnFe}_{0.5} \mathrm{Al}_{1.5} \mathrm{O}_{4}$, and (c) $\mathrm{ZnFe}_{1.5} \mathrm{Al}_{0.5} \mathrm{O}_{4}$ powders to produce active species e.g. $\mathrm{OH}^{*}$ and $\mathrm{O}_{2}{ }^{-}{ }^{-}$for the decomposition of organic pollutants.

Fig. 12 Stability of $\mathrm{ZnFe}_{1.5} \mathrm{Al}_{0.5} \mathrm{O}_{4}$ powders shown by four reaction cycles for photodegradation of $\mathrm{RhB}, \mathrm{MB}, \mathrm{MO}$, and $\mathrm{MR}$.

Fig. 13 XRD patterns of $\mathrm{ZnFe}_{1.5} \mathrm{Al}_{0.5} \mathrm{O}_{4}$ powders after $4^{\text {th }}$-round use.

Fig. 14 Magnetic hysteresis curves of pure $\mathrm{ZnAl}_{2} \mathrm{O}_{4}, \mathrm{ZnFe}_{0.5} \mathrm{Al}_{1.5} \mathrm{O}_{4}$, and $\mathrm{ZnFe}_{1.5} \mathrm{Al}_{0.5} \mathrm{O}_{4}$ powders.

Fig. 15 A photograph of the removal of modified aluminate photocatalyst by applying an external magnetic field after the completion of the photocatalytic reaction.

\section{TABLE CAPTIONS}

Table 1 Interplanar spacing $(d)$ and average crystallite size $(D)$ calculated by Scherrer and Williamson-Hall equations of $\mathrm{ZnFe}_{x} \mathrm{Al}_{2-\mathrm{x}} \mathrm{O}_{4}$ powders with different $\mathrm{Fe}^{3+}$ ion concentrations.

Table 2 Elemental composition of $\mathrm{Zn}, \mathrm{Fe}, \mathrm{Al}$, and $\mathrm{O}$ in the $\mathrm{ZnFe}_{\mathrm{x}} \mathrm{Al}_{2-\mathrm{x}} \mathrm{O}_{4}$ powders with different $\mathrm{Fe}^{3+}$ ion concentrations.

Table 3 Surface area $\left(S_{B E T}\right)$ and energy band gap $\left(E_{g}\right)$ of $\mathrm{ZnFe}_{\mathrm{x}} \mathrm{Al}_{2-\mathrm{x}} \mathrm{O}_{4}$ powders with different $\mathrm{Fe}^{3+}$ ion concentrations. 
Table 4 Summary of first order rate constant $k\left(\mathrm{~min}^{-1}\right)$ of $\mathrm{ZnFe}_{\mathrm{x}} \mathrm{Al}_{2-\mathrm{x}} \mathrm{O}_{4}$ powders with different $\mathrm{Fe}^{3+}$ ion concentrations for the degradation of $\mathrm{RhB}, \mathrm{MB}, \mathrm{MO}$, and MR. 
Figures

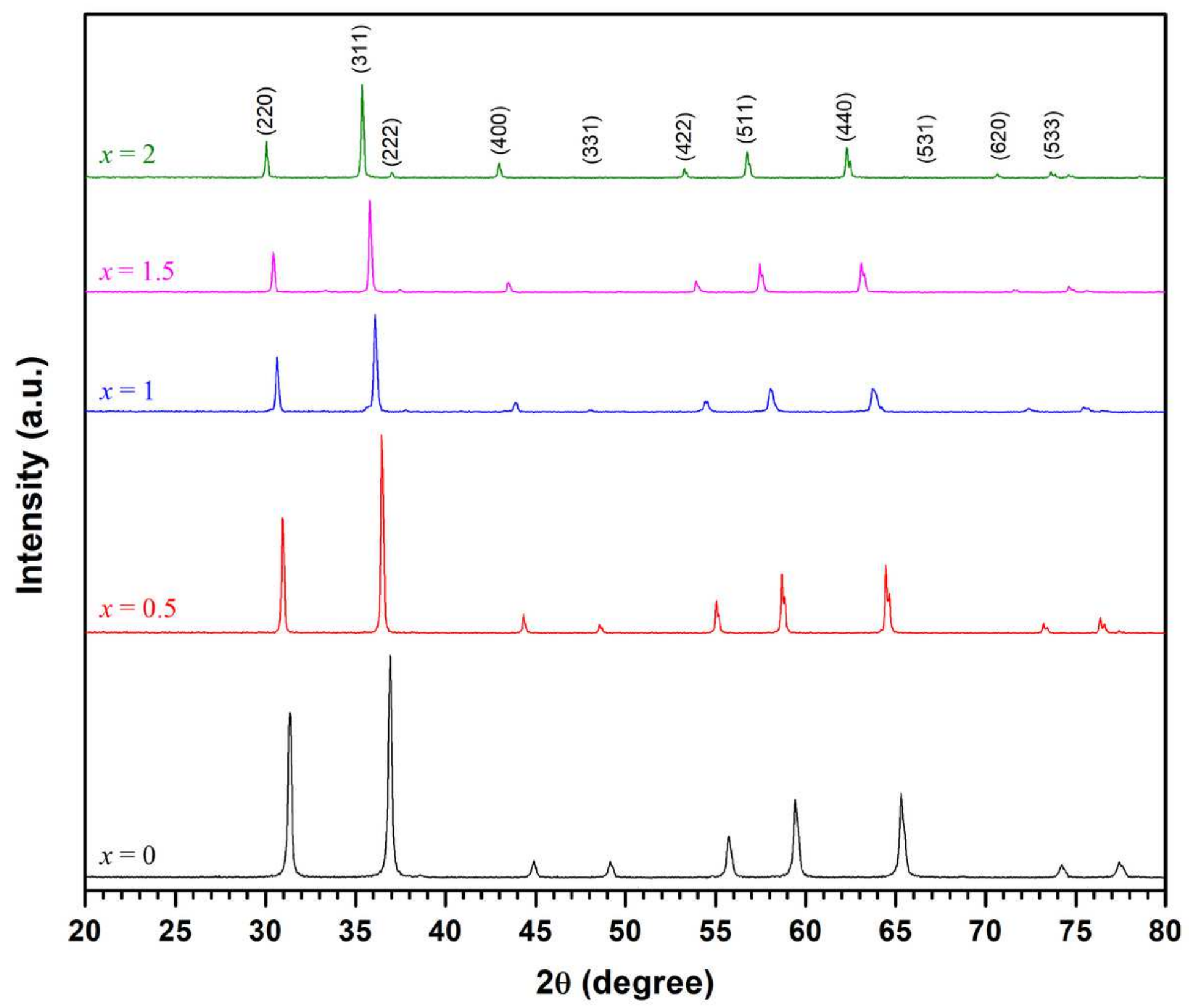

Figure 1

XRD patterns of ZnFexAl2-xO4 powders with different Fe3+ ion concentrations. 

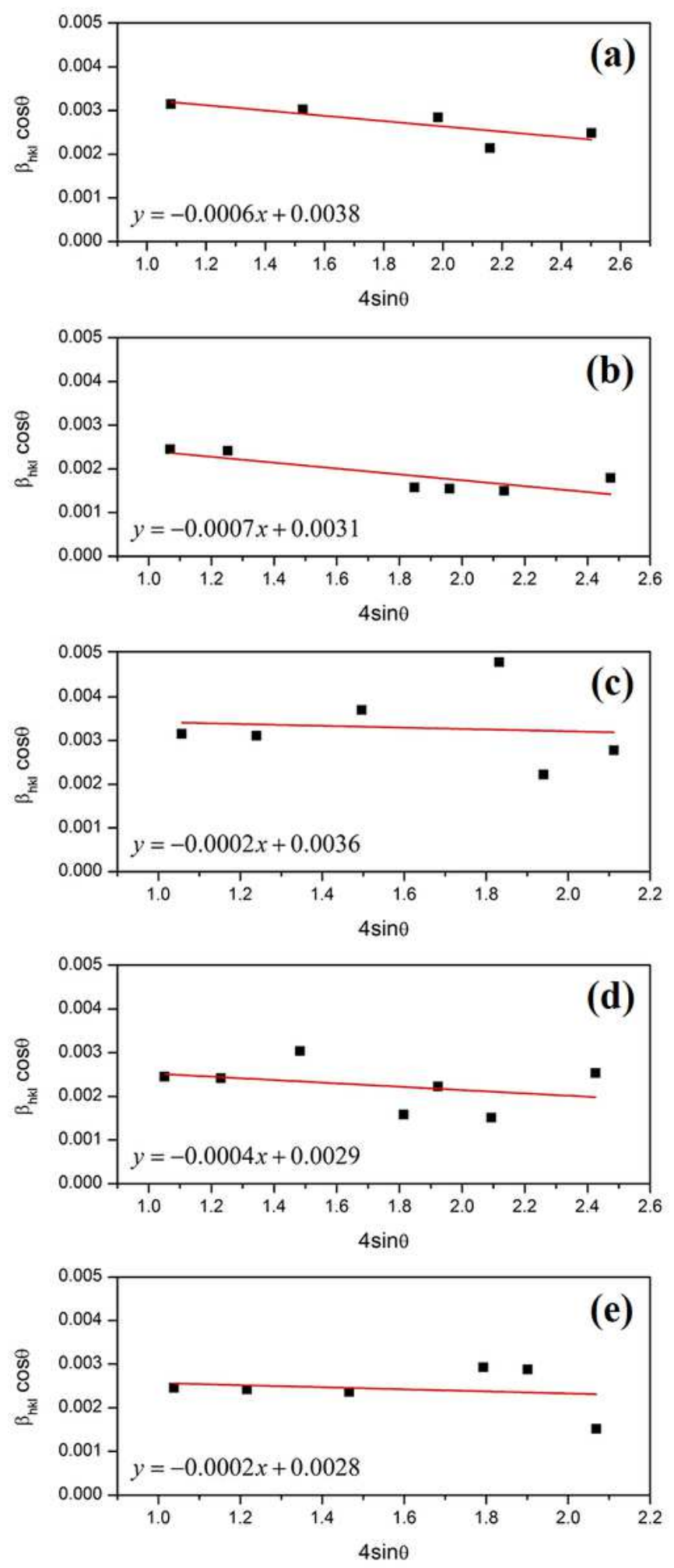

\section{Figure 2}

Plot of versus for (a) ZnAl204, (b) ZnFe0.5Al1.504, (c) ZnFeAlO4, (d) ZnFe1.5Al0.504, and (e) ZnFe2O4 powders. 


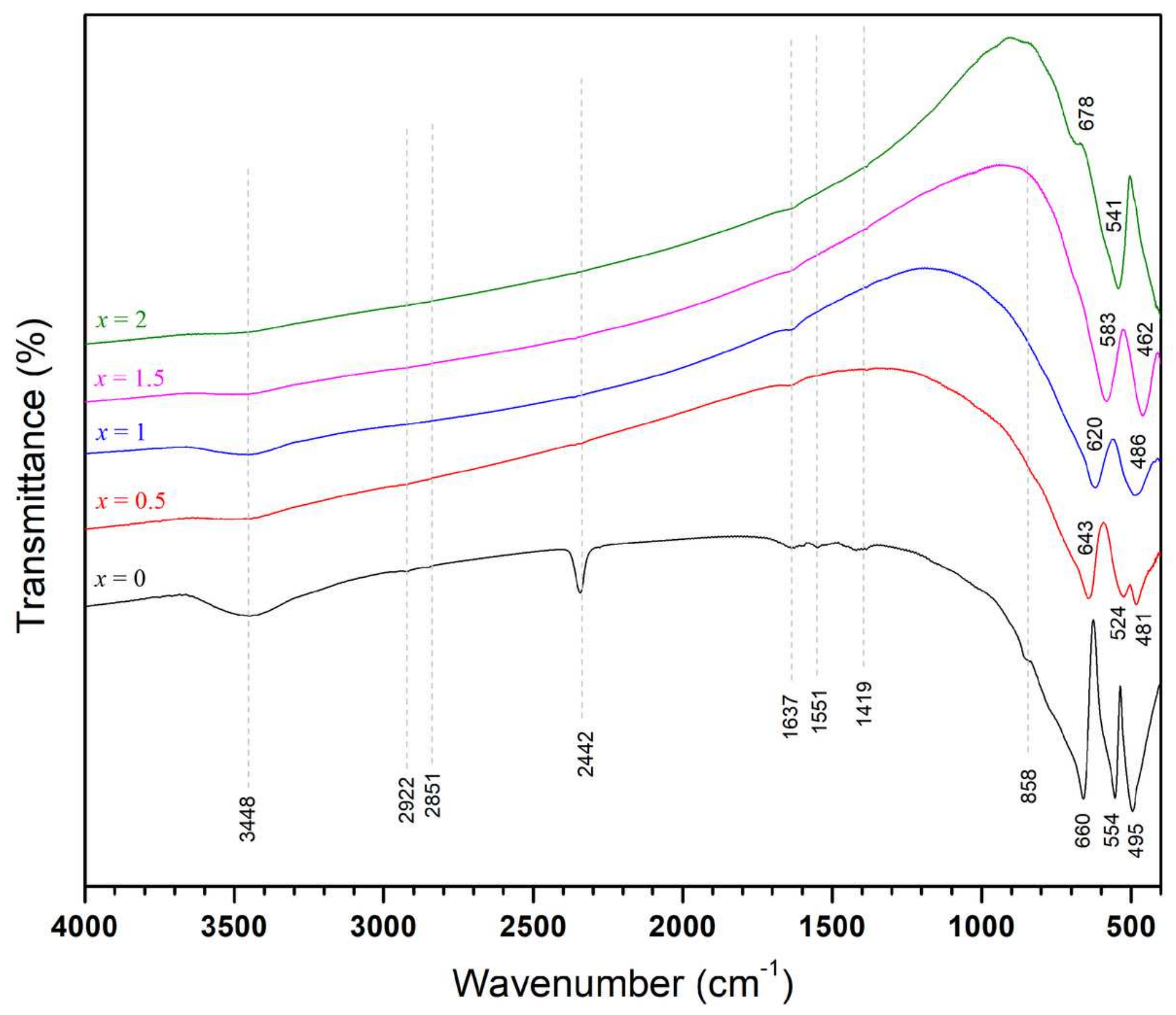

Figure 3

FT-IR spectra of ZnFexAl2-xO4 powders with different Fe3+ ion concentrations. 

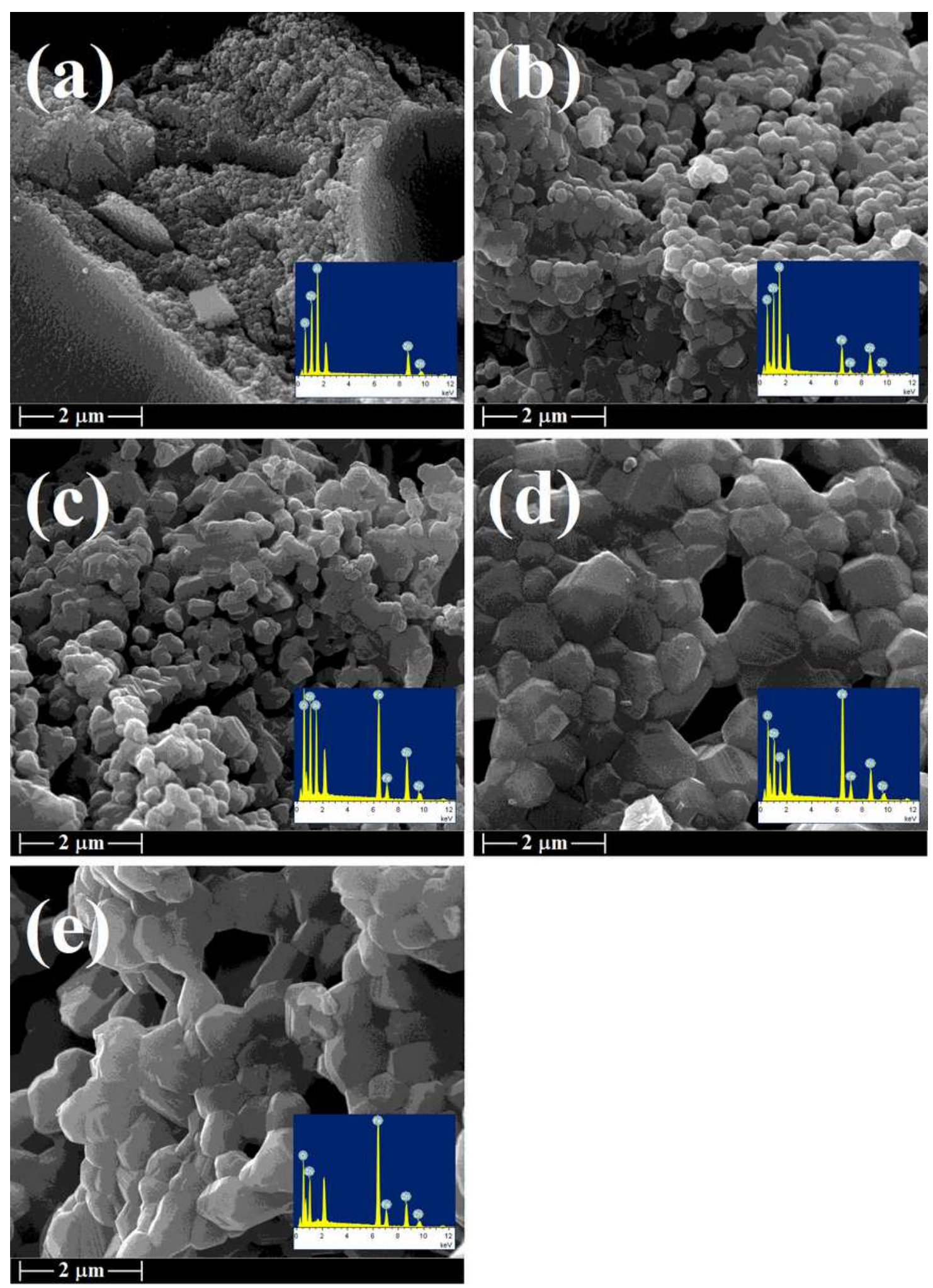

Figure 4

SEM images and EDS spectra of (a) ZnAl204, (b) ZnFe0.5Al1.504, (c) ZnFeAlO4, (d) ZnFe1.5Al0.504, and (e) ZnFe2O4 powders. 


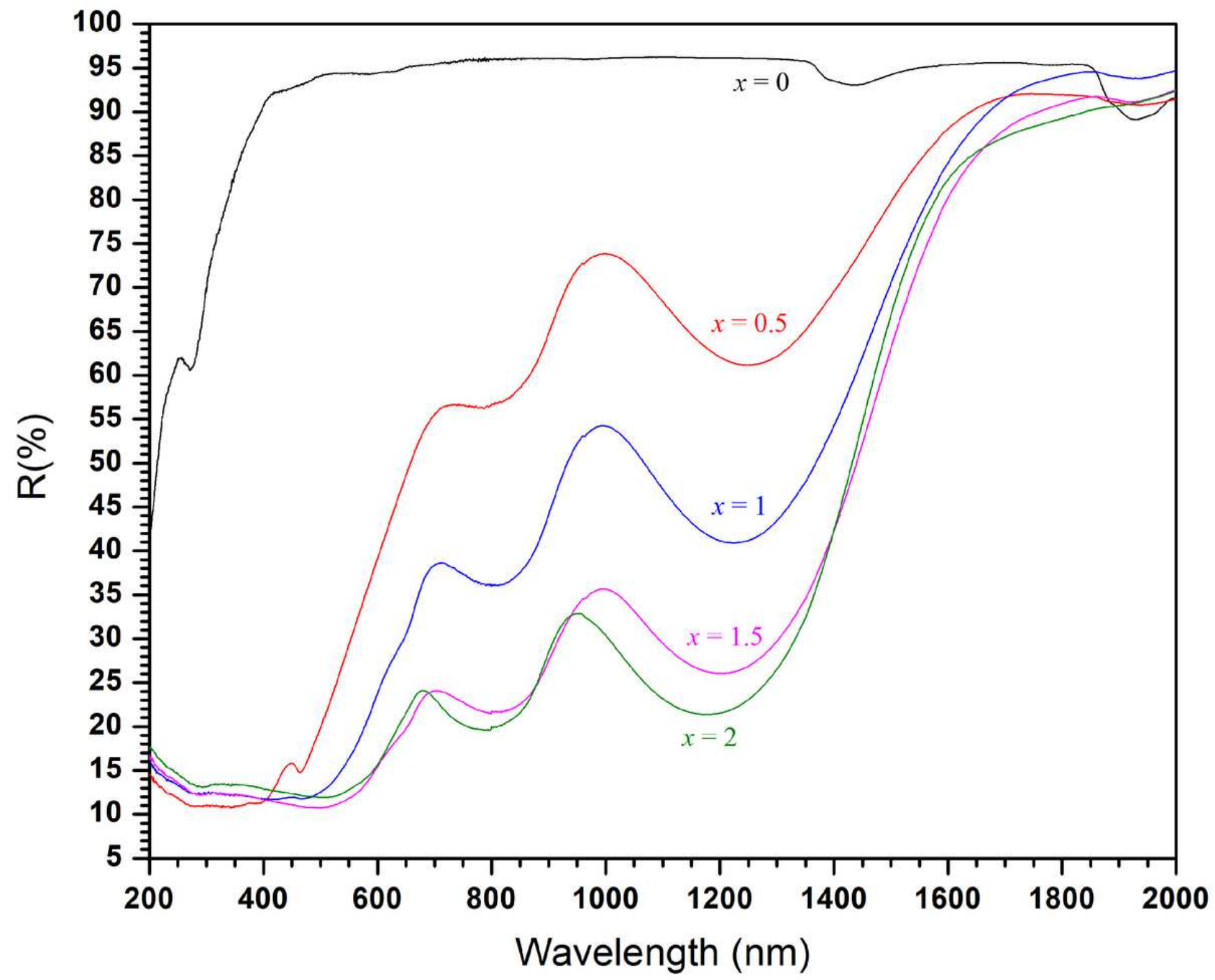

Figure 5

UV-Visible diffuse reflectance spectra of ZnFexAl2-xO4 powders with different $\mathrm{Fe} 3+$ ion concentrations. 

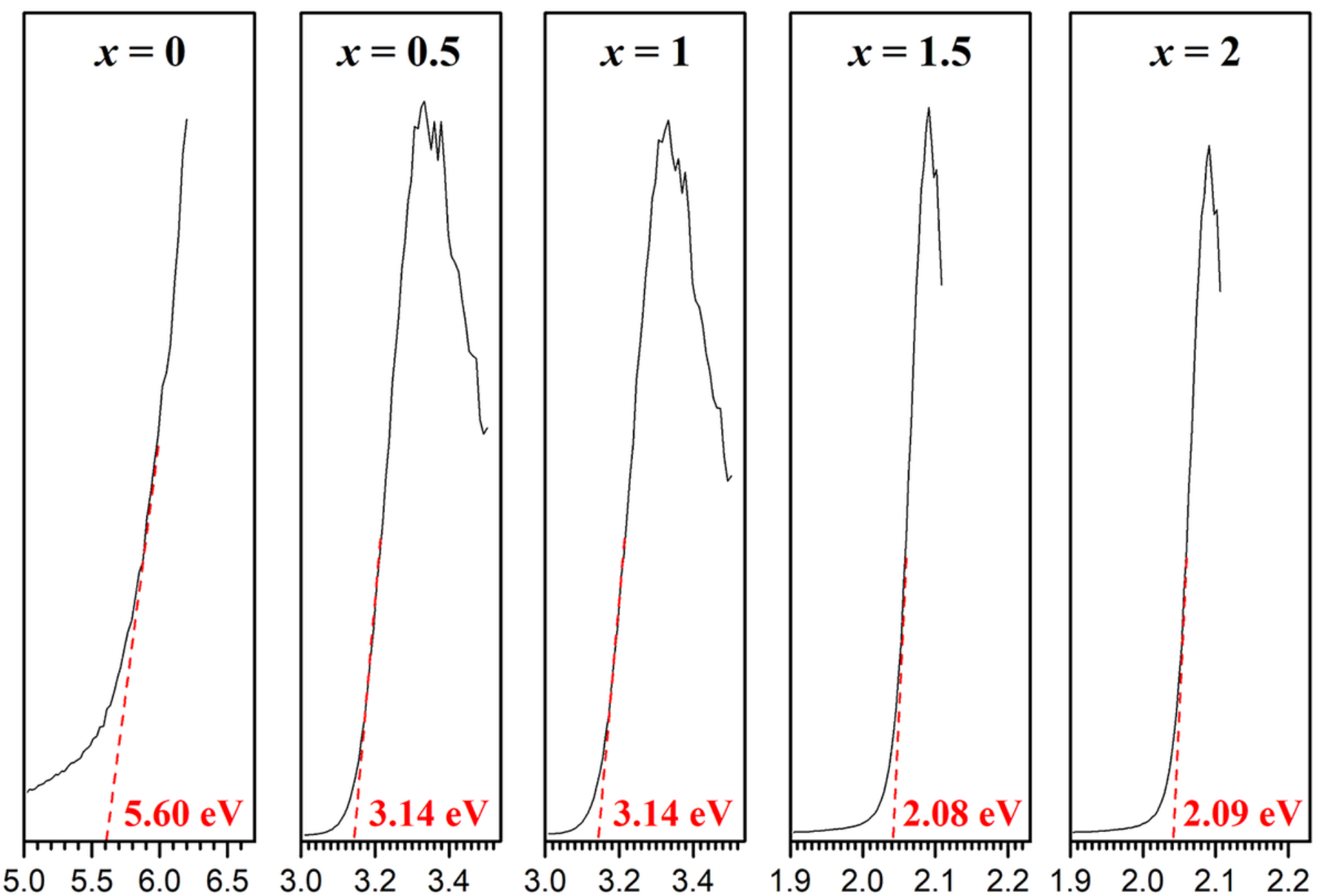

\section{Figure 6}

Plot of $(F(R) h v) 2$ versus hv for $\mathrm{ZnFexAl2-xO4}$ powders with different $\mathrm{Fe} 3+$ ion concentrations. 

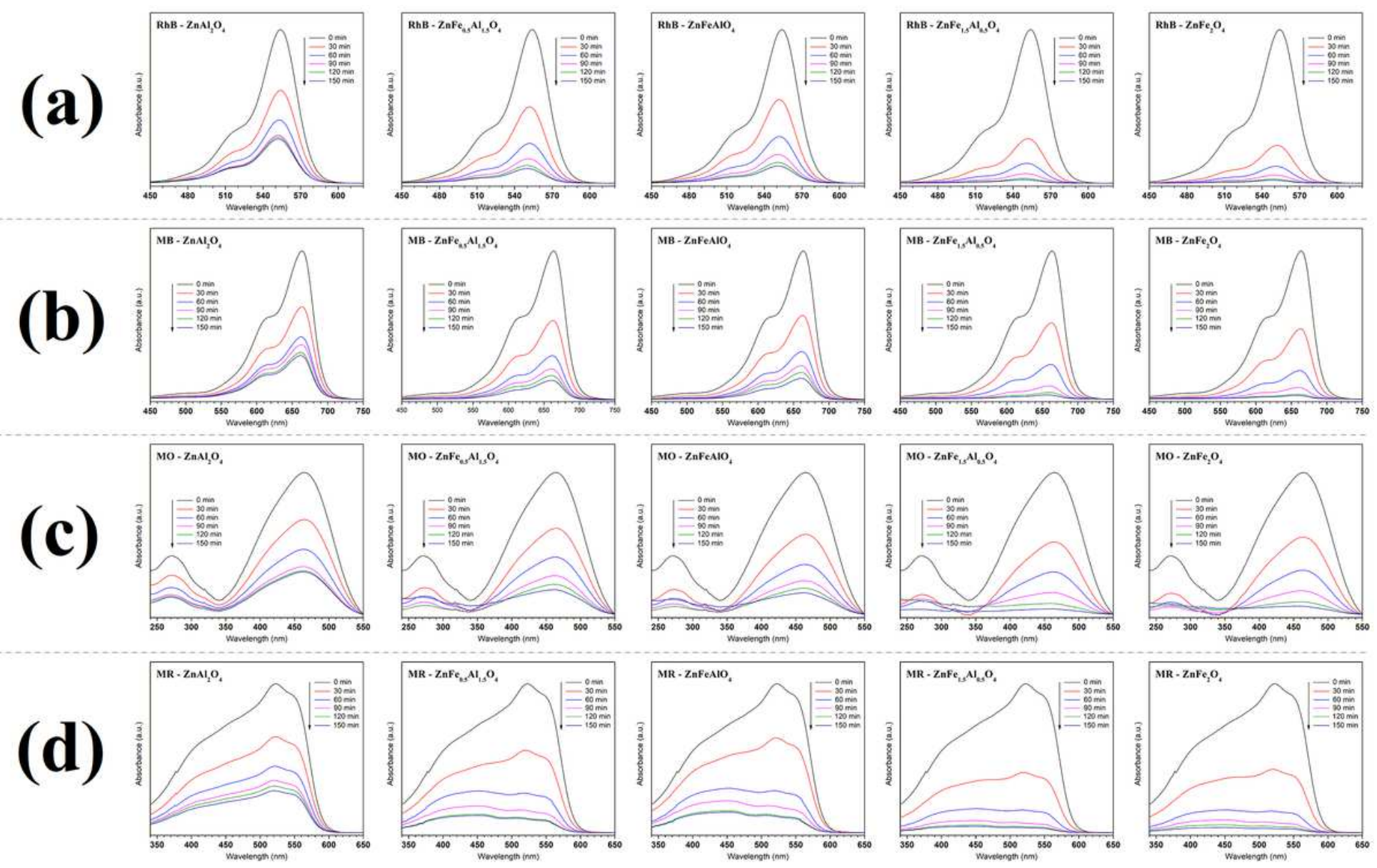

Figure 7

UV-Vis absorption spectra for the degradation of (a) RhB, (b) MB, (c) MO, and (d) MR solutions in the presence of $\mathrm{ZnFexAl2-xO4}$ powders with different $\mathrm{Fe} 3+$ ion concentrations under sunlight irradiation. 

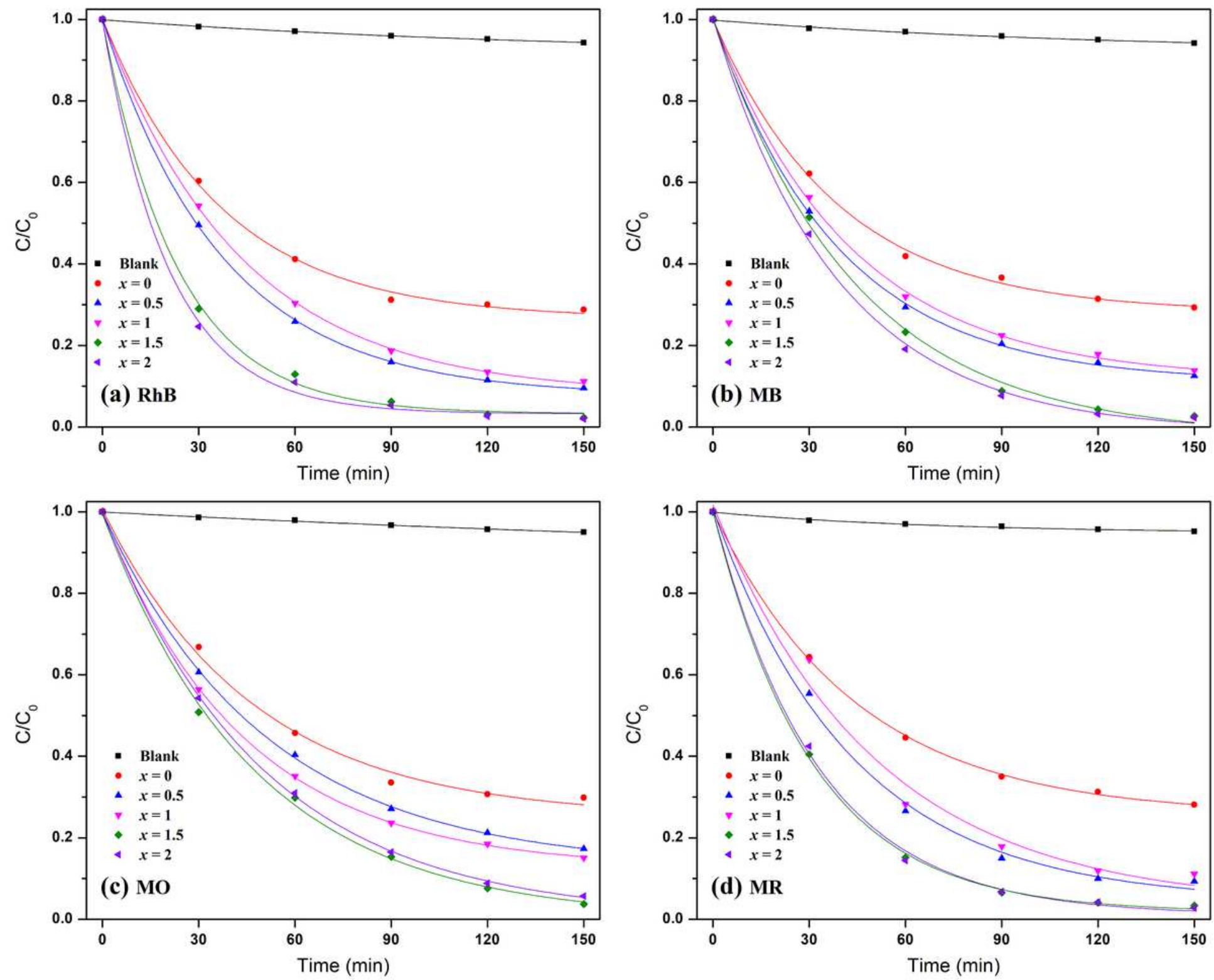

Figure 8

Residual concentration ratio (C/CO) of (a) RhB, (b) MB, (c) MO, and (d) MR as a function of time under sunlight irradiation for ZnFexAl2-xO4 powders with different Fe3+ ion concentrations. 

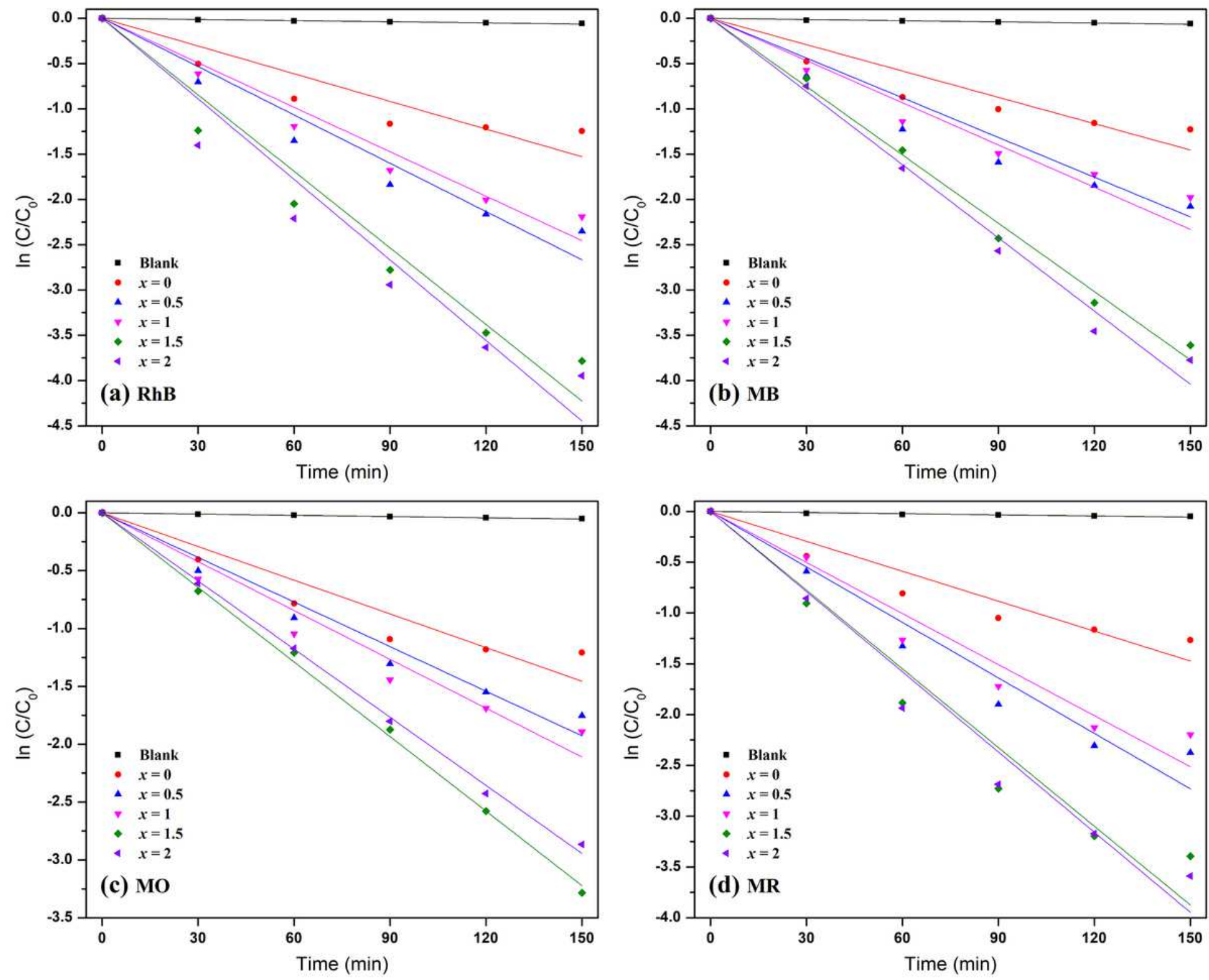

Figure 9

Kinetic curves of (a) RhB, (b) MB, (c) MO, and (d) MR degradation under sunlight irradiation in the presence of $\mathrm{ZnFexAl2-xO4}$ powders with different $\mathrm{Fe} 3+$ ion concentrations. 


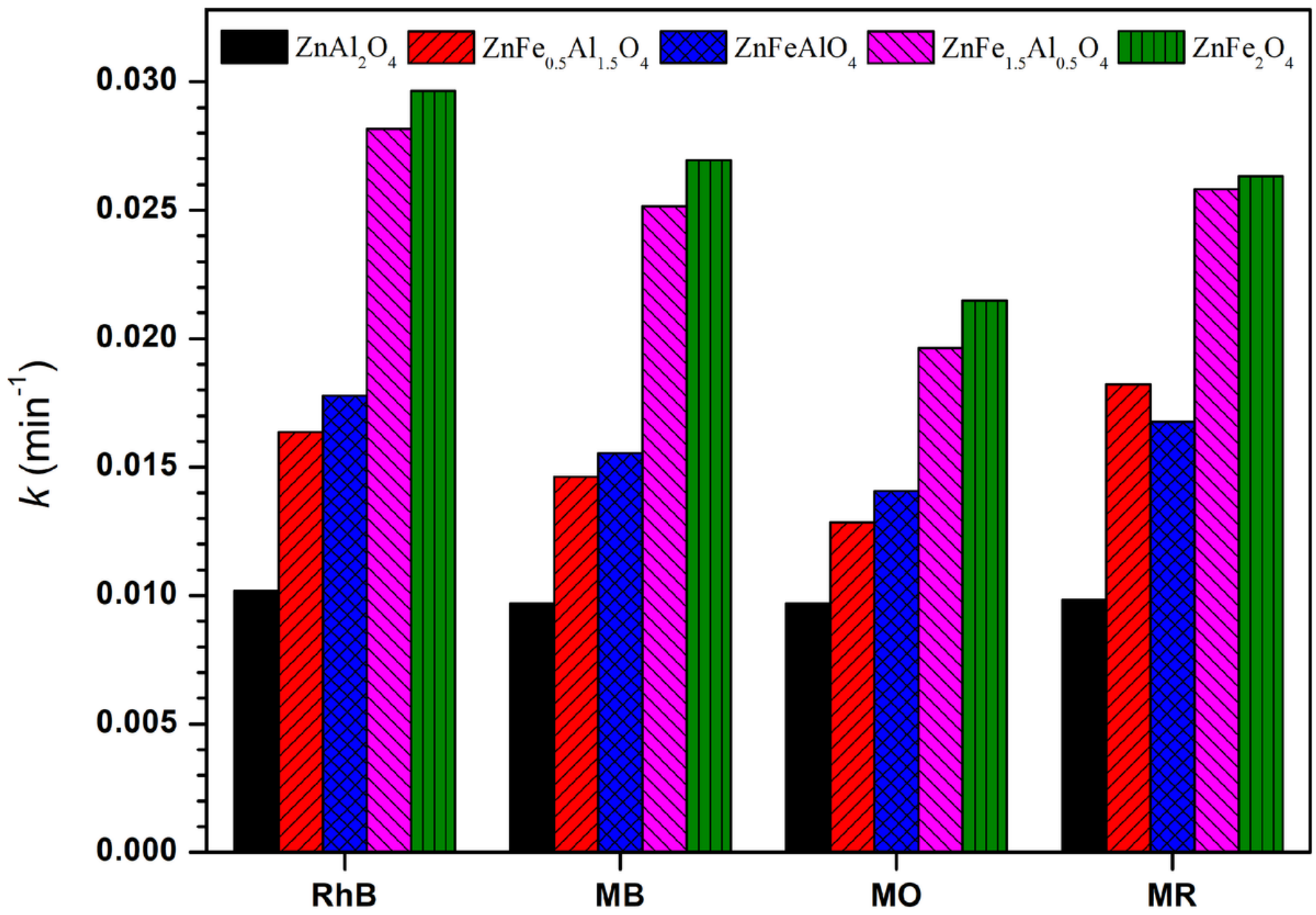

Figure 10

First order rate constant $\mathrm{k}$ (min-1) of $\mathrm{ZnFexAl2-xO4}$ powders with different $\mathrm{Fe} 3+$ ion concentrations for the degradation of $\mathrm{RhB}, \mathrm{MB}, \mathrm{MO}$, and $\mathrm{MR}$.

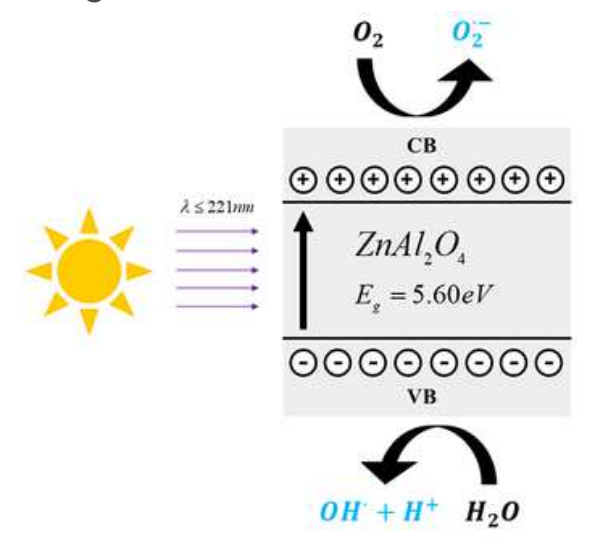

(a)

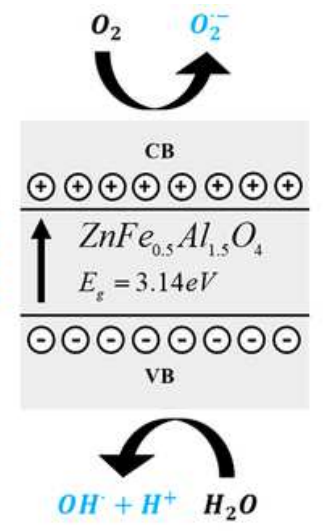

(b)

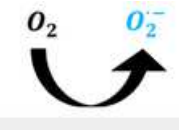

CB

$\oplus \oplus \oplus \oplus \oplus \oplus \oplus \oplus$

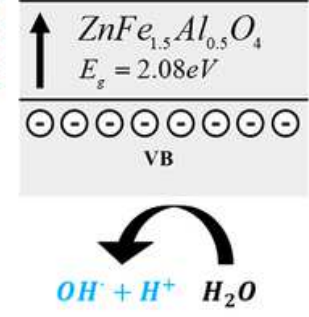

(c)

Figure 11 
Schematic illustration of possible mechanism of (a) pure ZnAl204, (b) ZnFe0.5Al1.504, and (c) ZnFe1.5Al0.504 powders to produce active species e.g. $\mathrm{OH}^{\prime}$ and $02-$ for the decomposition of organic pollutants.
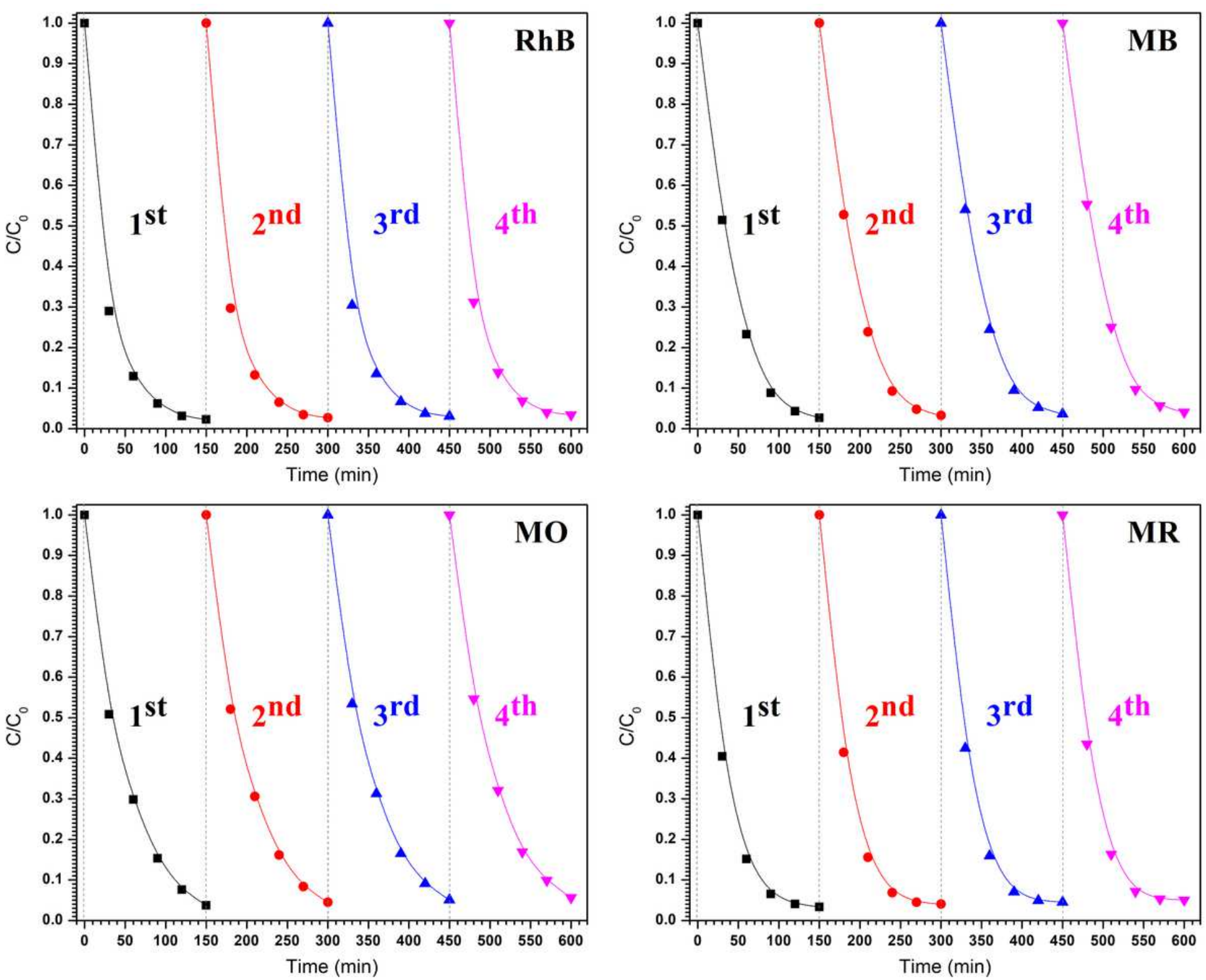

Figure 12

Stability of ZnFe1.5Al0.504 powders shown by four reaction cycles for photodegradation of RhB, MB, $\mathrm{MO}$, and MR. 


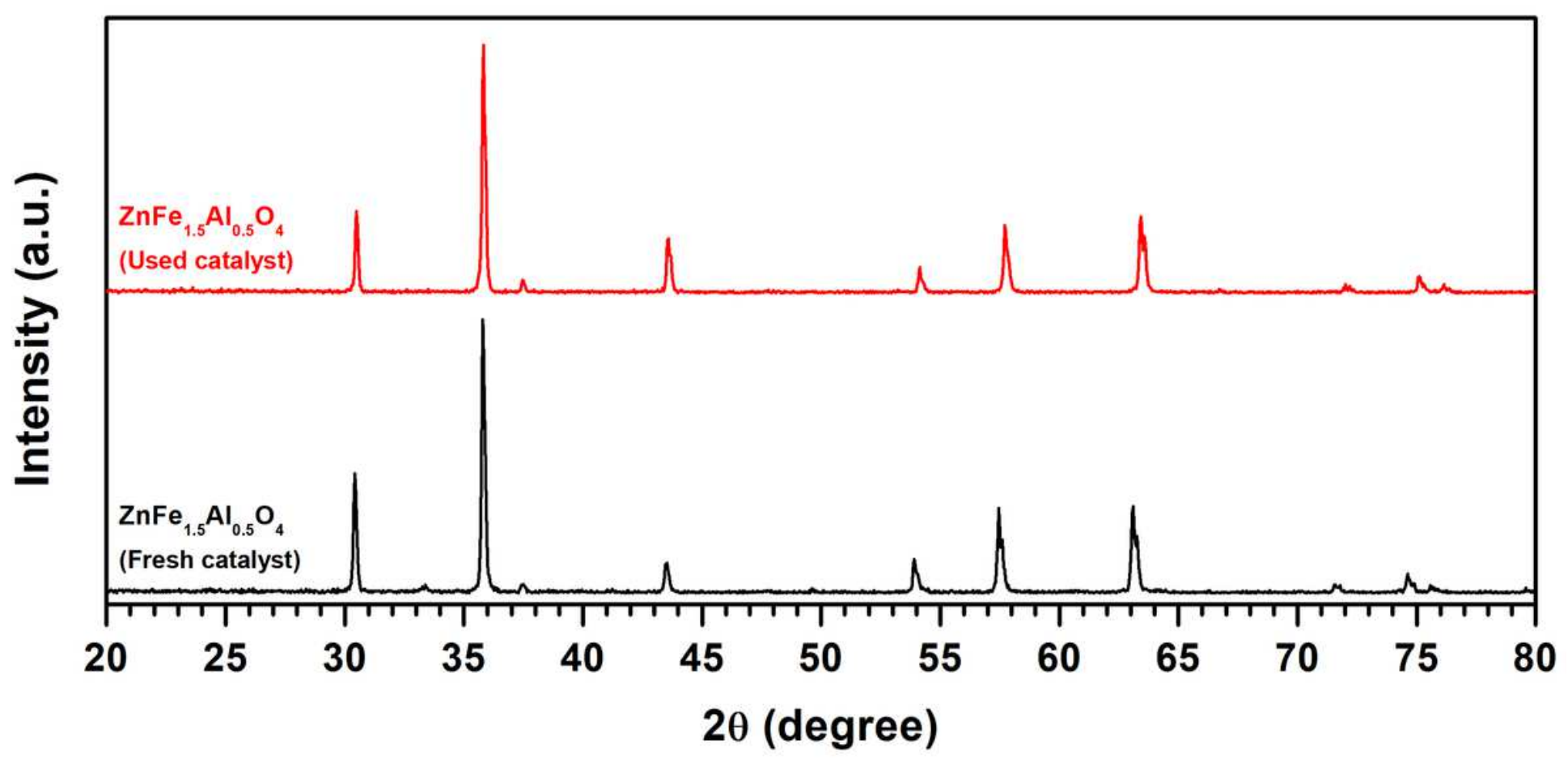

Figure 13

XRD patterns of ZnFe1.5Al0.504 powders after 4th-round use. 

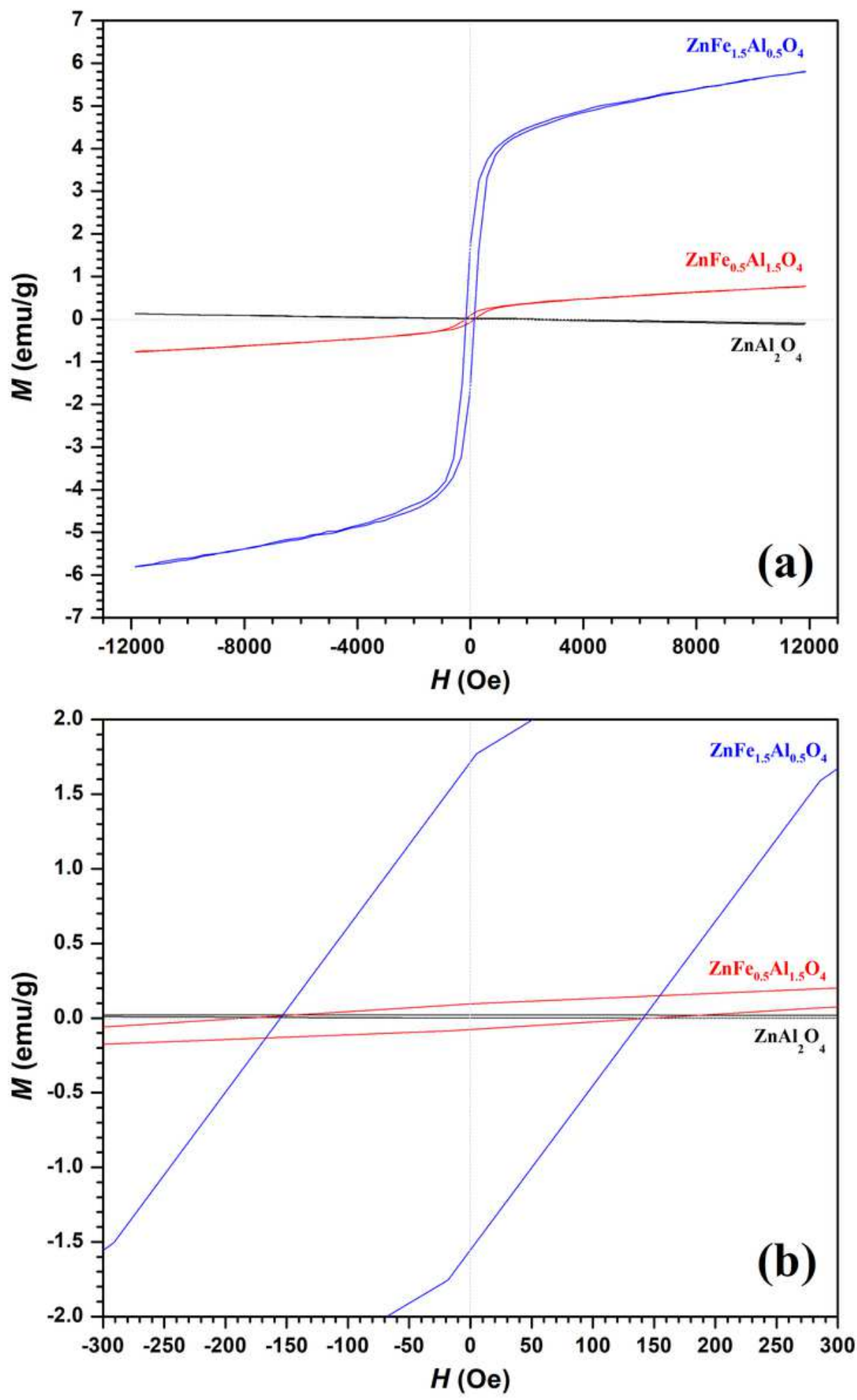

Figure 14

Magnetic hysteresis curves of pure ZnAl204, ZnFe0.5Al1.504, and ZnFe1.5Al0.504 powders. 

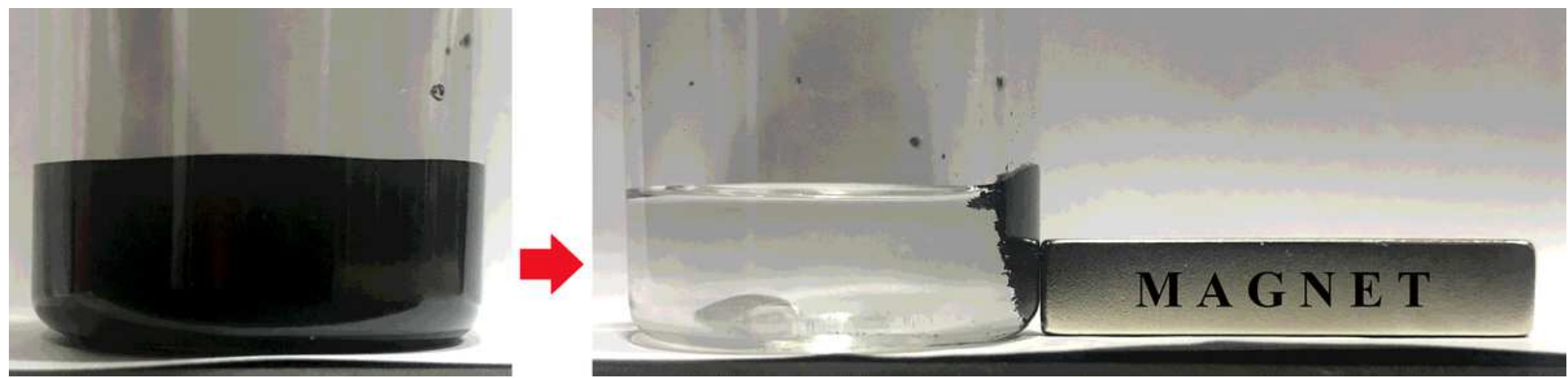

Figure 15

A photograph of the removal of modified aluminate photocatalyst by applying an external magnetic field after the completion of the photocatalytic reaction.

\section{Supplementary Files}

This is a list of supplementary files associated with this preprint. Click to download.

- Table1.xlsx

- Table2.xlsx

- Table3.xlsx

- Table4.xlsx 